\title{
Electrical and mechanical properties of (Bi,Pb)-2223 substituted by holmium
}

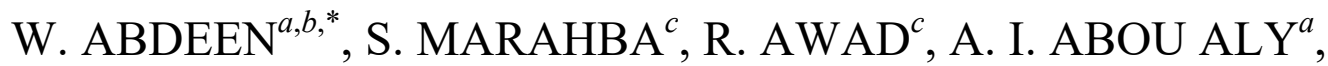 \\ I. H. IBRAHIM ${ }^{a}$, M. MATAR ${ }^{a}$ \\ ${ }^{a}$ Superconductivity and Metallic Glass Lab, Physics Department, Faculty of Science, \\ Alexandria University, Alexandria, Egypt \\ ${ }^{b}$ Physics Department, University College at Al-Gamom, Umm Al-Qura University, Saudi Arabia \\ ${ }^{c}$ Physics Department, Faculty of Science, Beirut Arab University (BAU), Beirut, Lebanon
}

Received: August 30, 2015; Revised: October 14, 2015; Accepted: October 15, 2015

(C) The Author(s) 2016. This article is published with open access at Springerlink.com

\begin{abstract}
The effect of the partial substitution of $\mathrm{Ca}^{2+}$ by $\mathrm{Ho}^{3+}$ ions on the electrical and mechanical properties of the superconducting phase $(\mathrm{Bi}, \mathrm{Pb})-2223$ was studied. Superconducting samples of the type $\left(\mathrm{Bi}_{1.8} \mathrm{~Pb}_{0.4}\right) \mathrm{Sr}_{2} \mathrm{Ca}_{2.1-x} \mathrm{Ho}_{x} \mathrm{Cu}_{3.1} \mathrm{O}_{10+\delta}$ were prepared by solid-state reaction technique under ambient pressure, and characterized by means of X-ray powder diffraction (XRD) and scanning electron microscopy (SEM). The superconducting transition temperature $T_{\mathrm{c}}$ and pseudogap temperature $T^{*}$ were estimated from electrical resistivity measurements, while the critical current density $J_{\mathrm{c}}$ was determined from $I-V$ curves. The electrical resistivity data were discussed according to bipolaron model in the absence of thermally excited individual polarons. The sample with $x=0.025$ showed the highest phase volume fraction, $T_{\mathrm{c}}$, and $J_{\mathrm{c}}$. Room temperature Vickers microhardness measurements were carried out at different applied loads $(0.25-5 \mathrm{~N})$ in order to investigate the performance of the mechanical properties of $\left(\mathrm{Bi}_{1.8} \mathrm{~Pb}_{0.4}\right) \mathrm{Sr}_{2} \mathrm{Ca}_{2.1-x} \mathrm{Ho}_{x} \mathrm{Cu}_{3.1} \mathrm{O}_{10+\delta}$ phase. It was found that all the samples exhibit normal indentation size effect (ISE). The Vickers microhardness number $H_{\mathrm{V}}$ increased as $x$ increased from 0 to 0.025 . The experimental results were discussed in view of Meyer's law, Hays-Kendall (HK) approach, elastic/plastic deformation (EPD) model, and proportional specimen resistance (PSR) model. The load independent (true) microhardness of $\left(\mathrm{Bi}_{1.8} \mathrm{~Pb}_{0.4}\right) \mathrm{Sr}_{2} \mathrm{Ca}_{2.1-x} \mathrm{Ho}_{x} \mathrm{Cu}_{3.1} \mathrm{O}_{10+\delta}$ superconducting samples showed identical behavior to that of the PSR model.
\end{abstract}

Keywords: (Bi,Pb)-2223 phase; Ho substitution; Vickers microhardness; bipolaron model; pesudogap temperature

\section{Introduction}

$(\mathrm{Bi}, \mathrm{Pb})-2223$ phase is the most promising one among the bismuth strontium calcium copper oxide (BSCCO)

\footnotetext{
* Corresponding author.

E-mail: waleed_abdeen@alex-sci.edu.eg
}

system to synthesize tapes and wires for large scale and high current applications, owing to its high superconducting transition temperature $T_{\mathrm{c}}$ and favorable characteristics such as atmospheric stability, high current and magnetic field carrying capacity, and electronic properties in view of a possible use in superconducting devices operated at liquid nitrogen temperature [1]. On the other hand, there are some 
problems which limit the practical applications of $(\mathrm{Bi}, \mathrm{Pb})-2223$; the most limiting parameters for the practical applications of this phase are critical current density $J_{\mathrm{c}}$ and mechanical properties [2]. Since the discovery of high temperature superconductors (HTSCs), many substitutions have been carried out in BSCCO system in order to improve its $T_{\mathrm{c}}$ and $J_{\mathrm{c}}$, and better understand the structural, physical, and mechanical properties [3-8]. The rare-earth element chemical substitution has an effective route in improving the flux pinning centers, which in turn enhance $J_{\mathrm{c}}$ and other transport properties of (Bi, $\mathrm{Pb})-2223$ phase [9]. The partial substitution of $\mathrm{Ca}^{2+}$ ions by rare-earth element $\mathrm{R}^{3+}$ ions on the $(\mathrm{Bi}, \mathrm{Pb})-2223$ phase has a significant effect on its normal and superconducting properties [10]. The previous studies showed that $T_{\mathrm{c}}$ values are gradually decreased with the increase of $\mathrm{R}^{3+}$ content [10-15]. The effect of partial substitution of $\mathrm{Sm}$ and $\mathrm{Eu}$ at $\mathrm{Ca}$ site in (Bi,Pb)-2223 system on the superconducting, microstructure, and mechanical properties was studied [12-16]. It was found that the volume fraction of $(\mathrm{Bi}, \mathrm{Pb})-2223$ phase decreases with increasing $\mathrm{Sm}$ content. Moreover, the superconducting properties and mechanical properties degrade with increasing Sm content. Also, $J_{\mathrm{c}}$ decreases by increasing Eu content and this decrease is related to the weakness of the grain connectivity and the increment of the porosity for $(\mathrm{Bi}, \mathrm{Pb})-2223$ phase. In addition, the lattice parameter $c$ decreases and the crystallographic structure is found to change slightly from tetragonal to orthorhombic.

The normal state properties of HTSCs, especially the metallic like behavior of electrical resistivity, can be discussed according to the bipolaron model [17]. Bipolarons could be created by the interaction between holes and optical phonons in HTSCs. Alexandrov and Mott [18] reported that for a system with large electron-phonon coupling constant, a Bose condensation of bipolarons can take place in the real space. Due to the extremely short coherence length of HTSCs, a cross-over region from Bardeen-CooperSchrieffer (BCS) to Bose-Einstein condensation (BEC) superfluids is considered in some theoretical studies related to their pairing mechanism. In the bipolaron model, however, BEC is only considered as paired state [19]. The bipolaron model is sensitive to both substitution concentration and sample crystal structure $[20,21]$.

The understanding of normal state properties of HTSCs would provide important evidences about the basic mechanisms responsible for superconductivity in
HTSCs. Thus, the normal state properties of HTSCs remain an area of intense research. One of the clearest differences between the BCS scenario of superconductivity and high $T_{\mathrm{c}}$ cuprates is the existence of a pseudogap. According to the band theory representation, pseudogap refers to some gapped regions in the Fermi surface, while other parts retain their conducting character. The chemical substitution changes the gapped region and metallicity of the material. The pseudogap is a fundamental property of the under-doped copper oxides, where the presence of pseudogap leads to striking deviation of resistivity from simple linear behavior [22-25]. However, the temperature dependence of resistivity for under-doped HTSCs shows a distinguishable deviation from linear behavior at the pseudogap temperature $T^{*}$. The recent literature indicated that, there are two scenarios for the explanation of the pseudogap temperature in HTSCs. According to the first scenario, pseudogap is related to short-range ordering fluctuations, e.g., antiferromagnetic fluctuations, spin, and charge density waves, etc. [22]. The second scenario assumes that Cooper pairs are formed at temperatures much higher than $T_{\mathrm{c}} ; T^{*}>T_{\mathrm{c}}$, and further phase coherence realizes at $T<T_{\mathrm{c}}[26,27]$.

The mechanical properties of small size samples can be measured using Vickers indentation method [28-31]. The effect of chemical substitution/addition on Vickers microhardness for (Bi,Pb)-2223 phase was studied by many groups [12-15,32-34]. It was found that the substitution of $\mathrm{Sm}$ at $\mathrm{Ca}$ site increases $H_{\mathrm{V}}$ due to the enhancement in grain connectivity, and the modified proportional specimen resistance model was found to be the most successful model describing the load independent microhardness [32]. Addition of $\mathrm{Gd}^{3+}$ ions to $(\mathrm{Bi}, \mathrm{Pb})-2223$ degrades the mechanical properties $[33,34]$. This degradation is related to the increase of voids, impurity phase segregation, and the modification of the grain boundaries.

In this work, we present a detailed study of the effect of $\mathrm{Ho}^{3+}$ substitution at $\mathrm{Ca}^{2+}$ site in $(\mathrm{Bi}, \mathrm{Pb})-2223$ phase. This study includes X-ray powder diffraction (XRD), scanning electron microscopy (SEM), electrical resistivity, $I-V$ characteristics, and Vickers microhardness for $\left(\mathrm{Bi}_{1.8} \mathrm{~Pb}_{0.4}\right) \mathrm{Sr}_{2} \mathrm{Ca}_{2.1-x} \mathrm{Ho}_{x} \mathrm{Cu}_{3.1} \mathrm{O}_{10+\delta}$ samples with $0.000 \leqslant x \leqslant 0.200$.

\section{Experimental details}

Conventional solid-state reaction technique was 
used to prepare superconducting samples of $\left(\mathrm{Bi}_{1.8} \mathrm{~Pb}_{0.4}\right) \mathrm{Sr}_{2} \mathrm{Ca}_{2.1-x} \mathrm{Ho}_{x} \mathrm{Cu}_{3.1} \mathrm{O}_{10+\delta}$ with $0.000 \leqslant x \leqslant$ 0.200. The starting materials were $\mathrm{Bi}_{2} \mathrm{O}_{3}, \mathrm{PbO}, \mathrm{PbO}_{2}$, $\mathrm{SrCO}_{3}, \mathrm{CaO}, \mathrm{CuO}$, and $\mathrm{Ho}_{2} \mathrm{O}_{3}$ (purity $\geqslant 99.9 \%$, Sigma-Aldrich). The stoichiometric mixture of the starting materials was ground manually in an agate mortar and sifted using a $65 \mu \mathrm{m}$ sieve. Then, the resulting powder was subjected to two stages of calcinations in air at $820{ }^{\circ} \mathrm{C}$ for $24 \mathrm{~h}$ for each with intermediate grinding and sieving. This is important to obtain the proper precursor phases necessary for the formation of $(\mathrm{Bi}, \mathrm{Pb})-2223$. The phase assemblage is sensitive to the calcination conditions [35]. After that, the mixture was cooled to room temperature and then ground and sifted. Then, the powder was pelletized into a disc with diameter of $1.5 \mathrm{~cm}$ and thickness of about $0.3 \mathrm{~cm}$ at a pressure of 15 tons $/ \mathrm{cm}^{2}$. The pellets were sintered in air (atmospheric pressure) at $845^{\circ} \mathrm{C}$ for $96 \mathrm{~h}$ with a heating rate of $4^{\circ} \mathrm{C} / \mathrm{min}$, and they were cooled with a rate of $2{ }^{\circ} \mathrm{C} / \mathrm{min}$ to room temperature. After that, the sintered samples were ground, sifted, and then pressed again in the form of disc and re-sintered in air at $845{ }^{\circ} \mathrm{C}$ for $48 \mathrm{~h}$ with a heating rate of $2{ }^{\circ} \mathrm{C} / \mathrm{min}$. Finally, the samples were cooled with a rate of $1{ }^{\circ} \mathrm{C} / \mathrm{min}$ to room temperature.

The prepared samples were characterized by XRD using a Philips X'Pert powder diffractometer with $\mathrm{Cu}$ $\mathrm{K} \alpha$ radiation $(\lambda=1.54056 \AA)$ in the range of $4^{\circ} \leqslant 2 \theta \leqslant$ $70^{\circ}$. The grain size and morphology of the samples' surface were identified using a Jeol scanning electron microscope JSM-5300, operated at $30 \mathrm{kV}$, with a resolution power of $4 \mathrm{~nm}$.

The electric resistivity of the prepared samples was measured by the conventional four-probe technique from room temperature down to zero resistivity temperature $T_{0}$ via a closed cryogenic refrigeration system (Displex) employing helium gas as a working medium. The transport critical current density was measured by the conventional four-probe technique at $77 \mathrm{~K}$ in a flow of liquid nitrogen using the standard $1 \mu \mathrm{V} / \mathrm{cm}$ criterion. The temperature of the samples was monitored by $\mathrm{Fe}-\mathrm{Au}$ thermocouple and stabilized with the aid of a temperature controller within $\pm 0.1 \mathrm{~K}$.

Vickers microhardness measurements of the studied samples were performed in atmospheric air at room temperature using a manual microhardness tester IN-412A. A Vickers pyramidal indenter with different applied loads varied from 0.25 to $5.00 \mathrm{~N}$ and a loading time of $10 \mathrm{~s}$ was used to measure the diagonals of indentation with an accuracy of $\pm 0.1 \mu \mathrm{m}$. An average of 7 readings at different locations of specimen surface was taken to obtain sensible mean value for each load. The measurements were carried out in such a way that the distance between any two indentations was more than two times the diagonal of the indentation mark to avoid surface effects due to neighboring indentation. The Vickers microhardness is defined as the ratio of applied load to the pyramidal contact area of indentation, and it is calculated as [36]:

$$
H_{\mathrm{v}}=1854.4 \frac{F}{d^{2}}
$$

where $F$ is the applied load (N) and $d$ is the diagonal length of the indentation mark $(\mu \mathrm{m})$.

\section{Results and discussion}

\section{1 Characterization and investigation}

The XRD patterns for $\left(\mathrm{Bi}_{1.8} \mathrm{~Pb}_{0.4}\right) \mathrm{Sr}_{2} \mathrm{Ca}_{2.1-x} \mathrm{Ho}_{x} \mathrm{Cu}_{3.1}$ $\mathrm{O}_{10+\delta}$ samples with $x=0.000,0.025,0.075$, and 0.200 at room temperature are shown in Fig. 1. It is observed that most of the high-intensity peaks belong to tetragonal phase of $(\mathrm{Bi}, \mathrm{Pb})-2223$ with a space group $P 4 / \mathrm{mmm}$ [37]. There are a few low-intensity peaks belonging to other phases, such as $(\mathrm{Bi}, \mathrm{Pb})-2212$ and $\mathrm{Ca}_{2} \mathrm{PbO}_{4}$. These impurity phases are typically observed in the preparation of $(\mathrm{Bi}, \mathrm{Pb})-2223$ by solid-state reaction technique [10,35,37-39]. The notations "**" and "+" indicate the peaks of $(\mathrm{Bi}, \mathrm{Pb})-2212$ and $\mathrm{Ca}_{2} \mathrm{PbO}_{4}$, respectively. The characteristic peak intensity of (Bi,Pb)-2223 phase (002) increases as $x$ increases from 0.000 to 0.025 , indicating that the low content of Ho can enhance the phase formation of

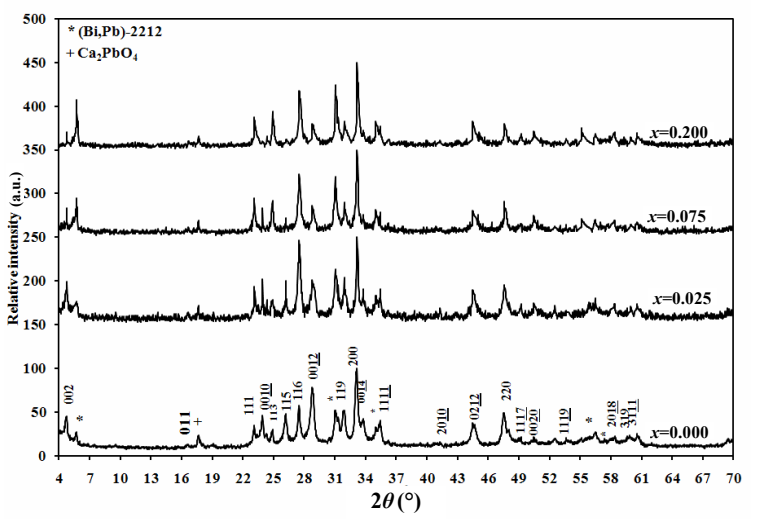

Fig. 1 XRD patterns for $\left(\mathrm{Bi}_{1.8} \mathrm{~Pb}_{0.4}\right) \mathrm{Sr}_{2} \mathrm{Ca}_{2.1-x} \mathrm{Ho}_{x} \mathrm{Cu}_{3.1} \mathrm{O}_{10+\delta}$ samples with $x=0.000,0.025,0.075$, and 0.200 at room temperature. 
(Bi, $\mathrm{Pb})-2223$ phase. For $x>0.025$, the intensity of characteristic peaks of $(\mathrm{Bi}, \mathrm{Pb})-2223$ decreases while the intensity of characteristic peaks of $(\mathrm{Bi}, \mathrm{Pb})-2212$ increases. This means that the high Ho content retards the growth of $(\mathrm{Bi}, \mathrm{Pb})-2223$ phase. Furthermore, no peaks belong to Ho rich compounds observed in the XRD patterns. This means that the Ho ions enter into the crystal structure of $(\mathrm{Bi}, \mathrm{Pb})-2223$. Similar results were reported for $(\mathrm{Bi}, \mathrm{Pb})-2223 / \mathrm{Ag}$ taps substituted by $\mathrm{Pr}$ ions at $\mathrm{Ca}$ site [40]. This indicates the high solubility limit of Ho in the crystal structure of (Bi, $\mathrm{Pb})-2223$ phase.

The relative volume fractions of $(\mathrm{Bi}, \mathrm{Pb})-2223$, $(\mathrm{Bi}, \mathrm{Pb})-2212$, and $\mathrm{Ca}_{2} \mathrm{PbO}_{4}$ phases are calculated using Eqs. (2)-(4), respectively $[5,10,28,37]$, and their values are listed in Table 1 with Ho content.

$(\mathrm{Bi}, \mathrm{Pb})-2223(\%)=$

$$
\frac{\sum I_{(\mathrm{Bi}, \mathrm{Pb})-2223}}{\sum I_{(\mathrm{Bi}, \mathrm{Pb})-2223}+\sum I_{(\mathrm{Bi}, \mathrm{Pb})-2212}+\sum I_{\mathrm{Ca}_{2} \mathrm{PbO}}} \times 100 \%
$$

$(\mathrm{Bi}, \mathrm{Pb})-2212(\%)=$

$$
\frac{\sum I_{(\mathrm{Bi}, \mathrm{Pb})-2212}}{\sum I_{(\mathrm{Bi}, \mathrm{Pb})-2223}+\sum I_{(\mathrm{Bi}, \mathrm{Pb})-2212}+\sum I_{\mathrm{Ca}_{2} \mathrm{PbO}}} \times 100 \%
$$

$$
\begin{aligned}
& \mathrm{Ca}_{2} \mathrm{PbO}_{4}(\%)= \\
& \frac{\sum I_{\mathrm{Ca}_{2} \mathrm{PbO}_{4}}}{\sum I_{(\mathrm{Bi}, \mathrm{Pb})-2223}+\sum I_{(\mathrm{Bi}, \mathrm{Pb})-2212}+\sum I_{\mathrm{Ca}_{2} \mathrm{PbO}_{4}}} \times 100 \%
\end{aligned}
$$

where $I$ represents the peak intensity of the indicated phases. A little increase in the volume fraction of $(\mathrm{Bi}, \mathrm{Pb})-2223$ phase is observed for $x=0.025$, and then it decreases for $x>0.025$, while the volume fraction of low- $T_{\mathrm{c}}$ phase $(\mathrm{Bi}, \mathrm{Pb})-2212$ decreases with $x=0.025$ and increases for $x>0.025$. These observations indicate that the low content of holmium enhances the formation of the (Bi,Pb)-2223 phase which could be due to the ability of Ho to provide a suitable medium for the conversion of the (Bi,Pb)-2212 phase to the $(\mathrm{Bi}, \mathrm{Pb})-2223$ phase and reduce the impure phases. While the further increase of $x$ leads to a change in the reaction rate which retards slightly the $(\mathrm{Bi}, \mathrm{Pb})-2223$ formation. A similar behavior was observed in many previous studies, concerning the effect of $\mathrm{R}^{3+}$ ions on $(\mathrm{Bi}, \mathrm{Pb})-2223$ phase [11-14].

The lattice parameters $a$ and $c$ were calculated using the least square method through $d$ value and $(h k l)$ planes for tetragonal unit cell structure. Their variations versus Ho content are also listed in Table 1. It is found that the lattice parameters $a$ and $c$ for the un-substituted sample are very close to those obtained
Table 1 Variation of the relative volume fraction of $(\mathrm{Bi}, \mathrm{Pb})-2223, \quad(\mathrm{Bi}, \mathrm{Pb})-2212$, and $\mathrm{Ca}_{2} \mathrm{PbO}_{4}$ phases, lattice parameters $a$ and $c$ for $\left(\mathrm{Bi}_{1.8} \mathbf{P b}_{0.4}\right) \mathbf{S r}_{2} \mathbf{C a}_{2.1-x}$ $\mathrm{Ho}_{x} \mathrm{Cu}_{3.1} \mathrm{O}_{10+\delta}$ phase with $0.000 \leqslant x \leqslant 0.200$

\begin{tabular}{ccccccc}
\hline \multirow{2}{*}{$x$} & \multicolumn{3}{c}{ Relative volume fraction $(\%)$} & \multicolumn{2}{c}{ Lattice parameter $(\AA)$} \\
\cline { 2 - 4 } \cline { 6 - 7 } & $(\mathrm{Bi}, \mathrm{Pb})-2223$ & $(\mathrm{Bi}, \mathrm{Pb})-2212$ & $\mathrm{Ca}_{2} \mathrm{PbO}_{4}$ & $a$ & $c$ \\
\hline 0.000 & 88.16 & 10.48 & 1.36 & $5.397(6)$ & $37.174(4)$ \\
0.025 & 89.89 & 8.92 & 1.19 & & $5.399(6)$ & $37.168(8)$ \\
0.050 & 84.86 & 13.95 & 1.18 & & $5.400(9)$ & $37.150(3)$ \\
0.075 & 82.58 & 15.99 & 1.43 & & $5.401(2)$ & $37.143(6)$ \\
0.100 & 81.42 & 17.08 & 1.50 & & $5.401(9)$ & $37.130(2)$ \\
0.150 & 80.75 & 17.50 & 1.74 & & $5.402(2)$ & $37.126(0)$ \\
0.200 & 79.50 & 18.15 & 2.35 & $5.402(4)$ & $37.120(1)$ \\
\hline
\end{tabular}

by Koyama et al. [41] and Abou-Aly et al. [42]. Moreover, for all substituted samples, the lattice parameter $a$ increases slightly with increasing Ho content while the lattice parameter $c$ decreases significantly. Similar behavior has been observed in previous works involving substitution of rare-earth elements at $\mathrm{Ca}$ site in the $(\mathrm{Bi}, \mathrm{Pb})-2223$ system $[10-13,43,44]$. This behavior can be explained according to two reasons. The first one is attributed to the partial substitution of larger ionic radius of $\mathrm{Ca}^{2+}$ ion, $0.990 \AA$, by the smaller one of $\mathrm{Ho}^{3+}$ ion, $0.901 \AA$, at the same 6-fold coordination type [45]. The second reason is that the partial substitution of $\mathrm{Ca}^{2+}$ ions by $\mathrm{Ho}^{3+}$ ions leads to an increase in the oxygen content of the unit cell that enhances the average oxidation state, leading to smaller $\mathrm{Cu}-\mathrm{O}$ distance within the copper-oxygen sheets [46]. In addition, the lattice parameter $a$ is controlled by the length of the in-plane $\mathrm{Cu}-\mathrm{O}$ bond which may be expanded as a result of electron addition into anti-bonding orbital through the partial substitution of $\mathrm{Ca}^{2+}$ ions by $\mathrm{Ho}^{3+}$ ions [47].

The SEM micrographs of the fractured surface of the prepared samples with $x=0.000,0.025,0.075$, and 0.200 are shown in Figs. 2(a)-2(d), respectively. The granular morphology for the un-substituted sample $x=$ 0 , consists primly of flaky layers of large platelet-like structure with random alignment distribution as shown in Fig. 2(a), which is a signature of $(\mathrm{Bi}, \mathrm{Pb})-2223$ phase formation $[48,49]$. The platelet grains are well linked as $x$ increases to 0.025 , in which the platelet-like grains still have a flaky structure. Additionally, the sample has more uniform surface appearance with larger average grain size and lower porosity as shown in Fig. 2(b). The average grain size increases from 1.99 to $2.27 \mu \mathrm{m}$ (calculated from the SEM) as Ho content increases from $x=0.000$ to $x=0.025$ and then decreases to $1.06 \mu \mathrm{m}$ for $x=0.200$. This indicates that the low Ho content increases the growth of $(\mathrm{Bi}, \mathrm{Pb})-2223$ phase, 


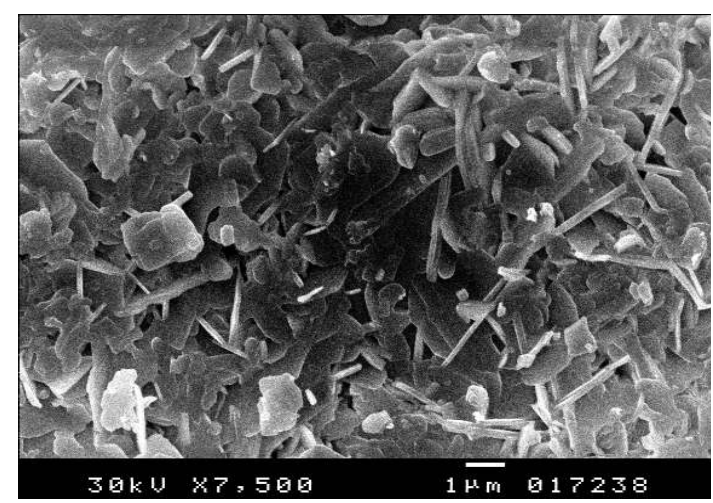

(a)

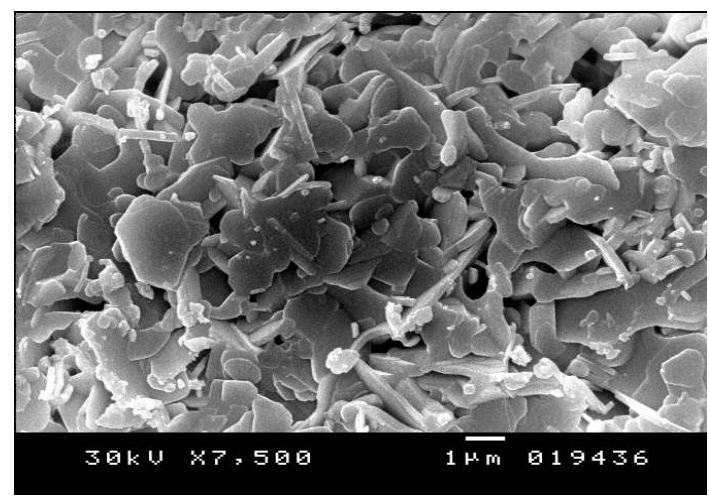

(b)

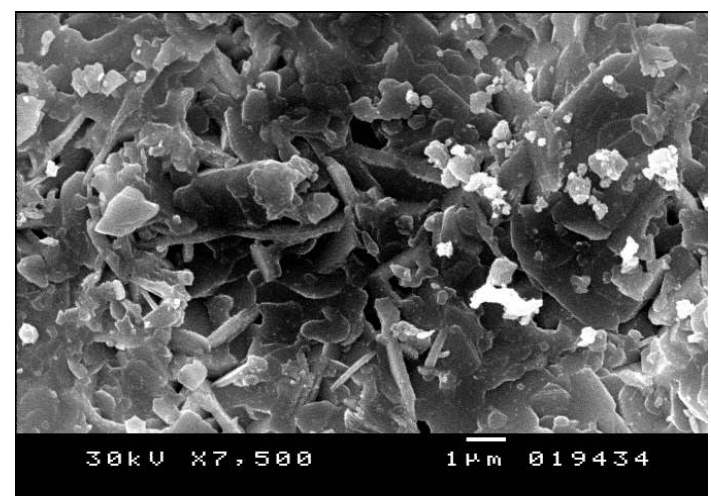

(c)

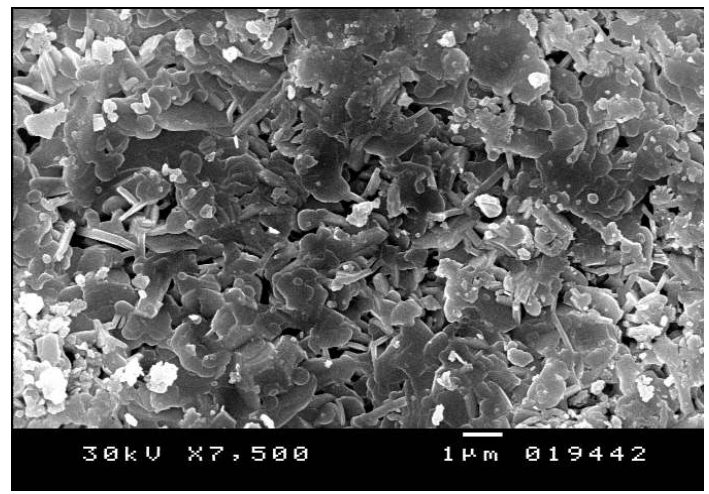

(d)

Fig. 2 SEM images of the fractured surface of the prepared samples $\left(\mathrm{Bi}_{1.8} \mathrm{~Pb}_{0.4}\right) \mathrm{Sr}_{2} \mathrm{Ca}_{2.1-x} \mathrm{Ho}_{x} \mathrm{Cu}_{3.1} \mathrm{O}_{10+\delta}$ with $x=$ (a) 0.000, (b) 0.025, (c) 0.075, and (d) 0.200. consistent with the enhancement of volume fraction of $(\mathrm{Bi}, \mathrm{Pb})-2223$ phase at low concentration. As the Ho content increases, the platelet shape is not changed, whereas the grain dimensions are changed and oriented randomly. The number of thin rectangular grains increases, indicating the increase in the low- $T_{\mathrm{c}}$ $(\mathrm{Bi}, \mathrm{Pb})-2212$ phase, voids, and hence porosity. Furthermore, the number of spherical grains refers to the $\mathrm{Ca}_{2} \mathrm{PbO}_{4}$ non-superconducting phase increasing. According to these observations, the surface morphology of the superconducting samples improves with the $\mathrm{Ho}^{3+}$ ions in the $(\mathrm{Bi}, \mathrm{Pb})-2223$ phase with $x=$ 0.025 . This may lead to the divergence from the optimum doping level and optimization of the hole concentration. Similar result was reported by Anis-ur-Rehman et al. [50] substituting $\mathrm{Ce}^{3+}$ ions at $\mathrm{Ca}$ site in $(\mathrm{Bi}, \mathrm{Pb})-2223$ phase.

The electrical resistivity of the superconducting samples $\left(\mathrm{Bi}_{1.8} \mathrm{~Pb}_{0.4}\right) \mathrm{Sr}_{2} \mathrm{Ca}_{2.1-x} \mathrm{Ho}_{x} \mathrm{Cu}_{3.1} \mathrm{O}_{10+\delta}$ with $x=$ $0.000,0.025,0.075$, and 0.200 as a function of temperature is shown in Fig. 3. All the prepared samples have a metallic-like behavior at high temperatures followed by a superconducting transition as the temperature is lowered. The normal metallic-like behavior above $T_{\mathrm{c}}$ can be interpreted by the liquid model and it reflects the spin charge separation in $\mathrm{CuO}_{2}$ planes that results in the longitudinal transport relaxation rate $1 / \tau \approx T$ [51]. It is noticed that the electrical resistivity behavior does not show the existence of a secondary phase at higher Ho contents, implying that the samples are mainly single phase. This result is consistent with that obtained through the X-ray investigation. A small curvature in electrical resistivity above $T_{\mathrm{c}}$ is observed for all

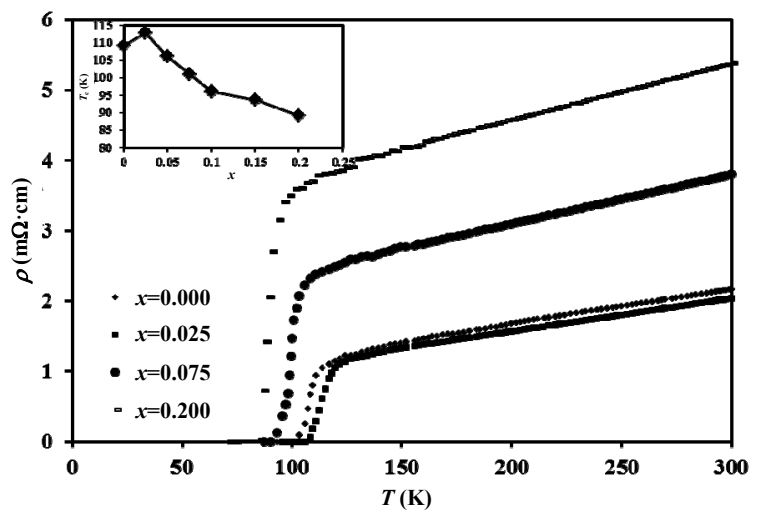

Fig. 3 Temperature dependence of the electrical resistivity for $\left(\mathrm{Bi}_{1.8} \mathrm{~Pb}_{0.4}\right) \mathrm{Sr}_{2} \mathrm{Ca}_{2.1-x} \mathrm{Ho}_{x} \mathrm{Cu}_{3.1} \mathrm{O}_{10+\delta}$ with $x=$ $0.000,0.025,0.075$, and 0.200 . The insert shows the variation of $T_{\mathrm{c}}$ with $x$. 
samples, which characterizes the superconducting thermodynamic fluctuations [52] or the opening of spin-gap that appears in the HTSCs due to magnetic impurity substitutions [53]. These superconducting thermodynamic fluctuations occur at finite temperatures just above $T_{\mathrm{c}}$ due to the appearance of Cooper pairs even above this temperature.

The superconducting transition temperature $T_{\mathrm{c}}$, which displays the superconducting transition within the grains, is determined as the temperature corresponding to the crest in $\mathrm{d} \rho / \mathrm{d} T$ versus $T$ curve [54]. The inset in Fig. 3 shows the variation of $T_{\mathrm{c}}$ with $x$ for $\left(\mathrm{Bi}_{1.8} \mathrm{~Pb}_{0.4}\right) \mathrm{Sr}_{2} \mathrm{Ca}_{2.1-x} \mathrm{Ho}_{x} \mathrm{Cu}_{3.1} \mathrm{O}_{10+\delta}$. It is clear that $T_{\mathrm{c}}$ enhances as $x$ increases from 0.000 to 0.025 and then it decreases with the further increase in $x$. The parabolic dependence of $T_{\mathrm{c}}$ on $x$ is considered to be a typical character of the substituted high temperature superconductors [11]. This relation indicates that the un-substituted sample lies in the under-doped region [12]. The enhancement of $T_{\mathrm{c}}$ can be explained according to the increase in the formation of $(\mathrm{Bi}, \mathrm{Pb})-2223$ and well linked grains for $0.000<x \leqslant$ 0.025 . It is also probably due to a change of the average oxidation state of copper as reported by Laximi Narasaiah et al. [55] substituting $\mathrm{Y}^{3+}$ ions in (Bi, $\mathrm{Pb})-2223$. They found an increase in $T_{\mathrm{c}}$ at low $\mathrm{Y}$ content. There are two different explanations for the strong depression of $T_{\mathrm{c}}$ for $x>0.025$. The first one due to Abrikosov-Gor'kov theory [56] is related to a Cooper pair breaking mechanism as a result of the magnetic ion substitution, and leads to a disorder in the internal magnetic state. The second one is due to the scattering between the Cooper pair and magnetic ions according to spin-flip process [57]. This process is characterized by total spin conservation in the scattering event, so the spin of Ho atom must flip when the Cooper pairs are broken. The location of carriers can play important role for enhancement or decrement of $T_{\mathrm{c}}$, which will discuss later by bipolaron model.

To compare our results with different $\mathrm{R}^{3+}$ substitution [58-60], the variation of the reduced transition temperature $\left(T_{\mathrm{c}}(x) / T_{\mathrm{c}}(0)\right)$ with rare-earth elements is plotted in Fig. 4. It is clear that, the critical concentration of $\mathrm{Ho}^{3+}$ ions required to destroy the superconductivity of (Bi, $\mathrm{Pb})-2223$ samples $(x>0.200)$ is higher than that reported for $\mathrm{Sm}^{3+}(x=0.2), \operatorname{Pr}^{3+}(x=$ $0.1)$, and $\mathrm{Ce}^{3+}$ or ${ }^{4+}(x=0.1)$ ions [58-60]. This indicates that $\mathrm{Ho}^{3+}$ ions have a higher solubility limit in the $(\mathrm{Bi}, \mathrm{Pb})-2223$ phase and are less detrimental to

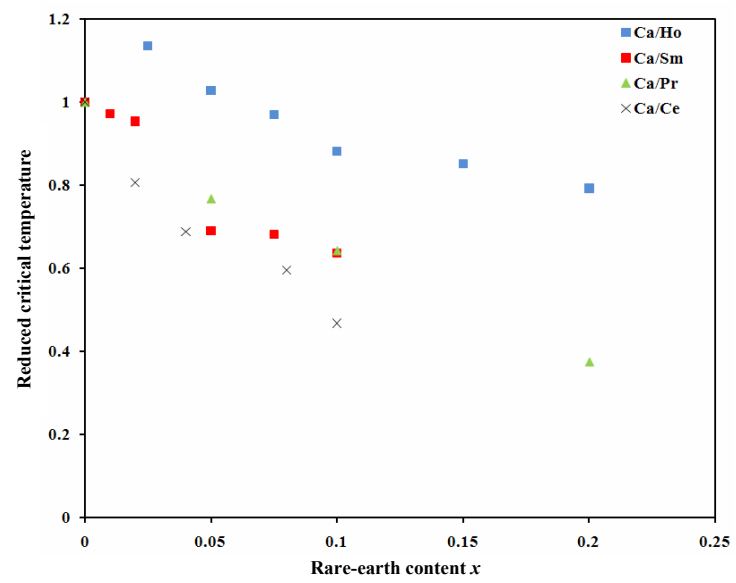

Fig. 4 Reduced critical temperature versus rare-earth content of $(\mathrm{Bi}, \mathrm{Pb})-2223$ samples.

superconductivity. The solubility limit of rare-earth elements $\mathrm{R}^{3+}$ in the $(\mathrm{Bi}, \mathrm{Pb})-2223$ phase can be understood by a comparison of their ionic radii of $0.901,0.958,0.990$, and $1.034 \AA$ for $\mathrm{Ho}^{3+}, \mathrm{Sm}^{3+}, \mathrm{Pr}^{3+}$, and $\mathrm{Ce}^{3+}$, respectively, with respect to $0.990 \AA$ of $\mathrm{Ca}^{2+}$ [45]. This means that the solubility limit may increase as the difference of ionic radii increases [10].

There are only a few models concerning the linear temperature dependence of the electrical resistivity of the HTSCs. One may exclude boson-boson and boson-phonon scatterings which are responsible for linear resistivity behavior at high and low temperatures, respectively [61]. Despite the polycrystalline nature of our samples, the data of electrical resistivity are analyzed using bipolaron model. In the first attempt of bipolaron model, normal state resistivity data are compared with a condition in which the contributions of the thermally excited individual polarons have not been taken into account [62]. This model is based on the localization of carriers by disorders and it predicts a linear behavior for the normal state resistivity. Considering the residual resistivity is zero, the temperature dependence of resistivity is given by Eq. (5):

$$
\rho=\left(\frac{m^{2} C V}{4 e^{2}}\right) \frac{T+\sigma_{\mathrm{b}} T^{2}}{N-N_{\mathrm{L}}+b N_{\mathrm{L}} T}
$$

where $m$ is the in-plane boson mass; $C$ is a constant proportional to the deformation potential; $V$ is the volume of the elementary cell; $N_{\mathrm{L}}$ is the number of localized states per unit cell; and $b N_{\mathrm{L}} T$ is the density of unoccupied potential wells. $\sigma_{\mathrm{b}}=\alpha e^{2} b N_{\mathrm{L}} /\left(m^{2} C\right)$ is the relative boson-boson scattering cross section in which $\alpha$ is a constant. 
The experimental electrical resistivity data and those fitted according to Eq. (5) are plotted in Fig. 5. In this figure, $\rho(T)$ deviates downwards from linear behavior at temperature $T^{*}$ corresponding to the pseudogap opening [63]. The fitting parameters for different substituted samples are listed in Table 2. The parameter $m^{2} C$, which corresponds to the rate of resistivity change, decreases slightly as Ho content $x$ increases to 0.025 and then it increases with further increase in $x$. The boson-boson scattering cross section can also alter the rate of resistivity change and its value increases by the increase of Ho concentration till $x=0.025$ and then has reverse trends for $x>0.025$. The number of localized states decreases slightly by substitution up to $x=0.025$. The localization of carriers by impurities may also play a useful role to describe $T_{\mathrm{c}}$ increment or suppression. The boson-boson relaxation time is proportional to parameter $b N_{\mathrm{L}}$ as $1 / \tau_{\mathrm{b}-\mathrm{b}}=$ $\left(\alpha e^{2} T^{2} / m\right) b N_{\mathrm{L}}$ and the increasing of $b N_{\mathrm{L}}$ for our data shows that Ho doping causes a decrease in $\tau_{\mathrm{b}-\mathrm{b}}$ value till $x=0.025$. A reverse trend is observed for $x>$ 0.025 .

The $T^{*}$ value is also determined by analyzing the

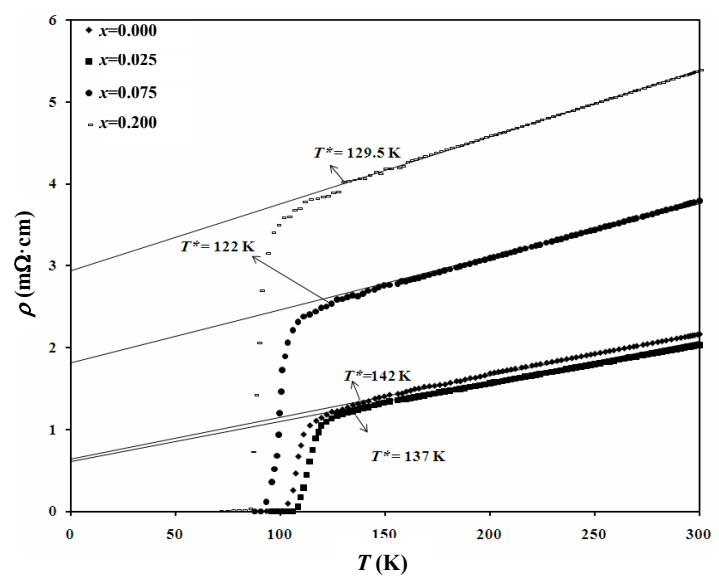

Fig. 5 Resistivity data for $\left(\mathrm{Bi}_{1.8} \mathrm{~Pb}_{0.4}\right) \mathrm{Sr}_{2} \mathrm{Ca}_{2.1-x} \mathrm{Ho}_{x} \mathrm{Cu}_{3.1} \mathrm{O}_{10+\delta}$ with $x=0.000,0.025,0.075$, and 0.200 compared with Eq. (5).

Table 2 Doping dependence of fitting parameters of Eq. (5) obtained from the experimental resistivity data

\begin{tabular}{ccccc}
\hline$x$ & $m^{2} C\left(10^{-20}\right)$ & $\sigma_{\mathrm{b}}\left(10^{-3}\right)$ & $N-N_{\mathrm{L}}\left(10^{-3}\right)$ & $b N_{\mathrm{L}}\left(10^{-4} \mathrm{~K}^{-1}\right)$ \\
\hline 0.000 & 75.85 & 6.38 & 1.50 & 9.31 \\
0.025 & 58.75 & 7.56 & 3.07 & 9.33 \\
0.050 & 74.16 & 6.75 & 2.37 & 6.88 \\
0.075 & 85.14 & 5.77 & 2.30 & 6.15 \\
0.100 & 85.23 & 3.38 & 2.15 & 4.50 \\
0.150 & 92.45 & 3.06 & 1.22 & 4.13 \\
0.200 & 92.73 & 3.04 & 1.09 & 3.99 \\
\hline
\end{tabular}

first derivative $\mathrm{d} \rho / \mathrm{d} T$ with respect to temperature at finite $\mathrm{d} \rho / \mathrm{d} T$ [64] as shown in Fig. 6. From the figure we can see that $(\mathrm{d} \rho / \mathrm{d} T) /(\mathrm{d} \rho / \mathrm{d} T)_{T=160 \mathrm{~K}}$ reduces as the temperature increases and then converges to a constant value at which $T^{*}$ can be determined. Table 3 displays the variation of $T^{*}$ values with $x$. It is clear that $T^{*}$ values decrease by increasing Ho content up to $x=0.100$ and then increase for $x \geqslant 0.150$. This enhancement can be explained by anti-ferromagnetic correlation in the $\mathrm{CuO}_{2}$ planes according to $t-J$ model or extended $t-J$ model [65], due to Ho substitution. The effective interplane coupling can be strongly enhanced by strong spin anti-ferromagnetic correlation, and extend over a coherence length of several lattice spacing. The enhanced coupling also leads to enhanced pairing between fermions on adjacent planes, thus is responsible for the formation of the spin gap [23]. In addition, it is observed that the values of pseudogap temperature estimated from the deviation of $\rho(T)$ from the linearity and those from the first derivative $\mathrm{d} \rho / \mathrm{d} T$ with respect to $\mathrm{d} \rho / \mathrm{d} T$ at finite temperature are nearly close to each others.

The $E-J$ curves for $\left(\mathrm{Bi}_{1.8} \mathrm{~Pb}_{0.4}\right) \mathrm{Sr}_{2} \mathrm{Ca}_{2.1-x} \mathrm{Ho}_{x} \mathrm{Cu}_{3.1}$

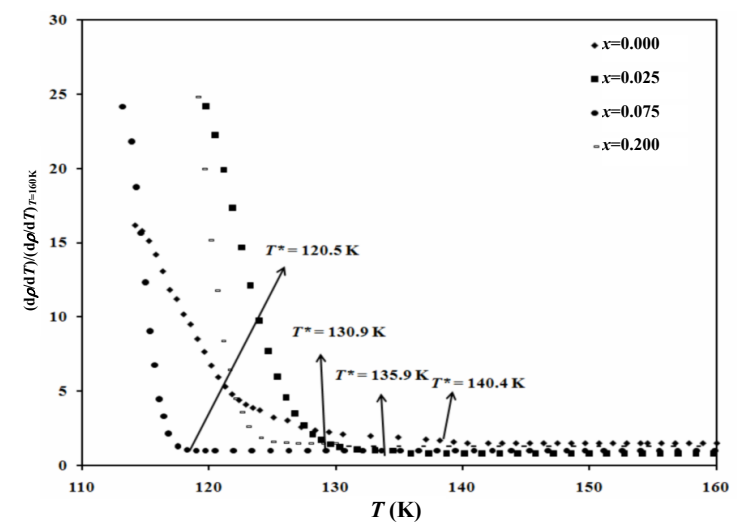

Fig. 6 Variation of $(\mathrm{d} \rho / \mathrm{d} T) /(\mathrm{d} \rho / \mathrm{d} T)_{T=160 \mathrm{~K}}$ versus $T$ curves for $\left(\mathrm{Bi}_{1.8} \mathrm{~Pb}_{0.4}\right) \mathrm{Sr}_{2} \mathrm{Ca}_{2.1-x} \mathrm{Ho}_{x} \mathrm{Cu}_{3.1} \mathrm{O}_{10+\delta}$ phase with $x=$ $0.000,0.025,0.075$, and 0.200 .

Table 3 Variation of $T^{*}$ with $x$ for $\mathrm{Bi}_{1.8} \mathrm{~Pb}_{0.4} \mathrm{Sr}_{2} \mathrm{Ca}_{2.1-x}$ $\mathrm{Ho}_{x} \mathrm{Cu}_{3.1} \mathrm{O}_{10+\delta}$ phase

\begin{tabular}{ccc}
\hline & \multicolumn{2}{c}{$T^{*}(\mathrm{~K})$} \\
\cline { 2 - 3 }$x$ & $\begin{array}{l}\text { Estimated from }(\mathrm{d} \rho / \mathrm{d} T) / \\
(\mathrm{d} \rho / \mathrm{d} T)_{T=160 \mathrm{~K}} \text { independent } \\
\text { on temperature }\end{array}$ & $\begin{array}{l}\text { Estimated } \\
\rho(T) \text { from linear behavior }\end{array}$ \\
\hline 0.000 & 140.4 & 142.0 \\
0.025 & 135.9 & 137.0 \\
0.050 & 126.5 & 124.5 \\
0.075 & 120.5 & 122.0 \\
0.100 & 110.7 & 111.0 \\
0.150 & 118.9 & 122.0 \\
0.200 & 130.9 & 129.5 \\
\hline
\end{tabular}


$\mathrm{O}_{10+\delta}$ with $x=0.000,0.025,0.075$, and 0.200 are shown in Fig. 7. The explanation of these curves can be divided into four parts as follows: (1) The system is resistanceless, $V(I)=0$, when the current is not large enough to cause vortex pair unbinding [66]. (2) At very low values of voltage, the linear $E-J$ behavior can be discussed according to the thermally assisted flux flow (TAFF) as the free vortices are created below $T_{\mathrm{c}}$ as a result of a finite penetration depth [67]. (3) In the non-linear behavior, the voltage drop appears at certain value of applied current $I_{\mathrm{c}}$, and this part can be understood as a result of the equality of Lorentz force and the pinning force, $F_{\mathrm{L}}=F_{\mathrm{p}}$. Therefore, one can expect to see flux creep due to the weak link junctions that impede the flux motion. (4) In the last linear region in the $E-J$ characteristic curve, the magnitude of the current increases and the Lorentz force is strong enough to cause vortex pair unbinding. So, this linear region in the $E-J$ characteristic curve can be discussed according to the flux flow which occurs at high values of applied current or high values of applied magnetic fields in which $F_{\mathrm{L}}>F_{\mathrm{p}}[68,69]$. The variation of $J_{\mathrm{c}}$ for $\left(\mathrm{Bi}_{1.8} \mathrm{~Pb}_{0.4}\right) \mathrm{Sr}_{2} \mathrm{Ca}_{2.1-x} \mathrm{Ho}_{x} \mathrm{Cu}_{3.1} \mathrm{O}_{10+\delta}$ with $0.000 \leqslant x \leqslant$ 0.200 is shown in the inset in Fig. 7. It is clear that the $J_{\mathrm{c}}$ values increase as Ho content increases from $x=$ 0.000 to $x=0.025$, and then decrease with further increase in $x$. The increase in $J_{\mathrm{c}}$ is related to the enhancement in the volume fraction of $(\mathrm{Bi}, \mathrm{Pb})-2223$, or the improving of grain boundaries. A similar result was observed by $\mathrm{Pu}$ et al. [40] when they substituted $\mathrm{Pr}^{3+}$ ions at $\mathrm{Ca}$ site with very small percentages in $(\mathrm{Bi}, \mathrm{Pb})-2223 / \mathrm{Ag}$ tapes. On the other hand, the formation of $(\mathrm{Bi}, \mathrm{Pb})-2212$ increases with

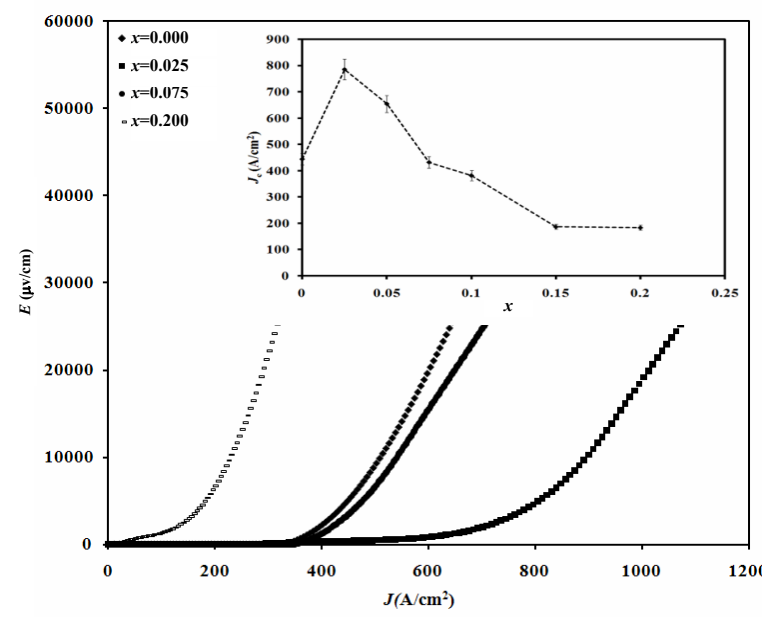

Fig. $7 E-J$ curves for $\left(\mathrm{Bi}_{1.8} \mathrm{~Pb}_{0.4}\right) \mathrm{Sr}_{2} \mathrm{Ca}_{2.1-x} \mathrm{Ho}_{x} \mathrm{Cu}_{3.1} \mathrm{O}_{10+\delta}$ with $x=0.000,0.025,0.075$, and 0.200 . The inset shows the variation of $J_{\mathrm{c}}$ with $x$. $x>0.025$ and could be residual at the grain boundaries. This decreases the intergranular Josephson coupling energy and hence decreases of the pinning of intergranular vortices [70]. Thus, one can contribute the decrease in $T_{\mathrm{c}}$ and $J_{\mathrm{c}}$ with increasing Ho content to the suppression of the relative volume fraction for $(\mathrm{Bi}, \mathrm{Pb})-2223$ phase and the growth of the impurity content, as well as the increase in porosity accompanied with the increase in grain boundary weak links. This result is in consistent with the XRD data.

\section{2 Mechanical measurements}

The room temperature Vickers microhardness $H_{\mathrm{V}}$ is calculated for $\left(\mathrm{Bi}_{1.8} \mathrm{~Pb}_{0.4}\right) \mathrm{Sr}_{2} \mathrm{Ca}_{2.1-x} \mathrm{Ho}_{x} \mathrm{Cu}_{3.1} \mathrm{O}_{10+\delta}$ phase according to Eq. (1). $H_{\mathrm{V}}$ values are plotted as a function of the applied loads in Fig. 8 for samples with $x=0.000$, $0.025,0.075$, and 0.200 . The measured indentation diagonal length $(d)$ and the calculated Vickers microhardness $H_{\mathrm{V}}$ for all samples are listed in Table 4. It is observed that $H_{\mathrm{V}}$ increases by increasing Ho content from $x=0.000$ to $x=0.025$, and then it has a reverse trend for $x>0.025$. Thus, the low content of partial substitution of $\mathrm{Ca}^{2+}$ ions by $\mathrm{Ho}^{3+}$ ions has a significant effect on improving the microhardness of $(\mathrm{Bi}, \mathrm{Pb})-2223$ superconducting phase. This improvement can be attributed to the reduction of porosity and the improvement of the weak links between grains. This result is found to be consistent with the obtained SEM micrograph results. The decrease of the measured Vickers microhardness with increasing of Ho content for $x>0.025$ is quite similar to that obtained by

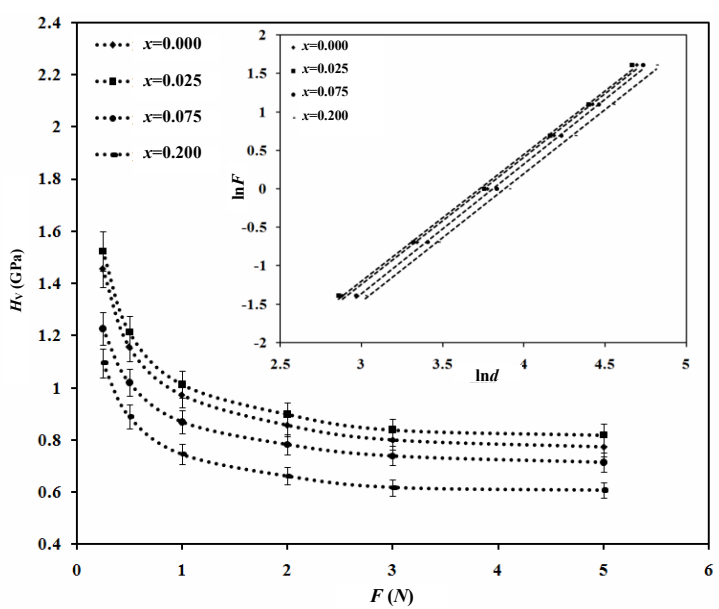

Fig. 8 Dependence of Vickers microhardness $H_{\mathrm{V}}$ on the applied load $F$ for $\left(\mathrm{Bi}_{1.8} \mathrm{~Pb}_{0.4}\right) \mathrm{Sr}_{2} \mathrm{Ca}_{2.1-x} \mathrm{Ho}_{x} \mathrm{Cu}_{3.1} \mathrm{O}_{10+\delta}$ with $x=0.000,0.025,0.075$, and 0.200 . The inset shows the variation of $\ln H_{\mathrm{V}}$ with $\ln d$ for $\left(\mathrm{Bi}_{1.8} \mathrm{~Pb}_{0.4}\right) \mathrm{Sr}_{2} \mathrm{Ca}_{2.1-x} \mathrm{Ho}_{x} \mathrm{Cu}_{3.1}$ $\mathrm{O}_{10+\delta}$ with $x=0.000,0.025,0.075$, and 0.200 . 
Table 4 Measured diagonal length and calculated microhardness value of BSCCO samples for different applied loads

\begin{tabular}{|c|c|c|c|c|c|c|c|}
\hline$x$ & $F(\mathrm{~N})$ & $H_{\mathrm{V}}(\mathrm{GPa})$ & $d(\mu \mathrm{m})$ & $x$ & $F(\mathrm{~N})$ & $H_{\mathrm{V}}(\mathrm{GPa})$ & $d(\mu \mathrm{m})$ \\
\hline \multirow{6}{*}{0.000} & 0.25 & 1.46 & 17.84 & \multirow{6}{*}{0.100} & 0.25 & 1.21 & 19.58 \\
\hline & 0.50 & 1.16 & 28.29 & & 0.50 & 0.98 & 30.76 \\
\hline & 1.00 & 0.97 & 43.63 & & 1.00 & 0.83 & 47.30 \\
\hline & 2.00 & 0.86 & 65.72 & & 2.00 & 0.74 & 70.90 \\
\hline & 3.00 & 0.80 & 83.29 & & 3.00 & 0.70 & 89.10 \\
\hline & 5.00 & 0.78 & 109.36 & & 5.00 & 0.68 & 117.00 \\
\hline \multirow{6}{*}{0.025} & 0.25 & 1.52 & 17.44 & \multirow{6}{*}{0.150} & 0.25 & 1.16 & 19.99 \\
\hline & 0.50 & 1.21 & 27.63 & & 0.50 & 0.94 & 31.41 \\
\hline & 1.00 & 1.01 & 42.76 & & 1.00 & 0.79 & 48.48 \\
\hline & 2.00 & 0.90 & 64.19 & & 2.00 & 0.70 & 72.71 \\
\hline & 3.00 & 0.84 & 81.38 & & 3.00 & 0.66 & 91.75 \\
\hline & 5.00 & 0.82 & 106.34 & & 5.00 & 0.64 & 120.45 \\
\hline \multirow{6}{*}{0.050} & 0.25 & 1.32 & 18.75 & \multirow{6}{*}{0.200} & 0.25 & 1.10 & 20.57 \\
\hline & 0.50 & 1.08 & 29.30 & & 0.50 & 0.89 & 32.28 \\
\hline & 1.00 & 0.92 & 44.90 & & 1.00 & 0.75 & 49.86 \\
\hline & 2.00 & 0.82 & 67.06 & & 2.00 & 0.66 & 74.85 \\
\hline & 3.00 & 0.78 & 84.72 & & 3.00 & 0.62 & 94.84 \\
\hline & 5.00 & 0.76 & 110.82 & & 5.00 & 0.61 & 123.53 \\
\hline \multirow{6}{*}{0.075} & 0.25 & 1.23 & 19.44 & & & & \\
\hline & 0.50 & 1.02 & 30.15 & & & & \\
\hline & 1.00 & 0.87 & 46.17 & & & & \\
\hline & 2.00 & 0.78 & 68.80 & & & & \\
\hline & 3.00 & 0.74 & 86.73 & & & & \\
\hline & 5.00 & 0.72 & 113.87 & & & & \\
\hline
\end{tabular}

Yilmazlar et al. [14] in $\mathrm{Bi}_{1.6} \mathrm{~Pb}_{0.4} \mathrm{Sr}_{2} \mathrm{Ca}_{2-x} \mathrm{Sm}_{x} \mathrm{Cu}_{3} \mathrm{O}_{y}$ phase. They attributed this behavior to the increase of void density and the resistance to crack propagation. The $H_{\mathrm{V}}-F$ curve behavior shows that the $H_{\mathrm{V}}$ decreases non-linearly as the applied load increases up to $3 \mathrm{~N}$, beyond which the curves tend to attain saturation (nearly plateau) region. This non-linear behavior is also observed for $(\mathrm{Bi}, \mathrm{Pb})-2223$ phase [12-15,30-34] and it is known as indentation size effect (ISE). The ISE behavior can be explained qualitatively on the basis of penetration depth of the indenter. Since the indenter penetrates only surface layers at small applied loads, the surface effect is more pronounced at these loads. However, as the depth of penetration increases, the effect of inner layers becomes more and more prominent, and ultimately there is no change in the values of hardness with applied load [71]. The substantial variation of microhardness is observed with increasing load between 0.25 and $3.00 \mathrm{~N}$. This behavior is due to the contribution of weak grain boundaries and the process of crack formation along grain boundaries [14]. The $H_{\mathrm{V}}-F$ results are analyzed according to different models as follows.

\section{2. 1 Meyer's law}

Meyer's law is the most basic method used in describing the ISE behavior [72,73]. It gives a relation between the applied load $F$ and the indentation diagonal length $d$ :

$$
F=A d^{n}
$$

where $A$ is a constant, representing the load needed to initiate unit indentation. The exponent $n$ is called Meyer's index and describes the ISE. The value of $n$ is less than 2 for normal ISE, while for reverse ISE, the value of $n$ is greater than 2 . When $n=2, H_{\mathrm{V}}$ is independent of the applied load. The typical plots of the dependence of $\ln F$ on $\ln d$ for $\left(\mathrm{Bi}_{1.8} \mathrm{~Pb}_{0.4}\right) \mathrm{Sr}_{2} \mathrm{Ca}_{2.1-x}$ $\mathrm{Ho}_{x} \mathrm{Cu}_{3.1} \mathrm{O}_{10+\delta}, x=0.000,0.025,0.075$, and 0.200 , superconducting samples are shown in the inset of Fig. 8, and the fitting parameters according to Eq. (6) is listed in Table 5. It is obvious from Table 5 that all prepared samples have $n<2$, indicating a normal ISE behavior. Here the values of $A$ are very small to be acceptable for the ceramic materials which are characterized by their high microhardness. Thus, Meyer's law can explain the ISE behavior of the data qualitatively well, but it cannot determine the true microhardness [34].

\section{2. 2 Hays-Kendall approach}

Hays-Kendall (HK) approach displays that there exists a minimum load $W$ (specimen resistance) to initiate plastic deformation below which only elastic deformation is occurred [74]. It is found that indentation size is proportional to an effective load 
$F_{\text {eff }}=F-W$ rather than the applied load itself, and the following relationship (modified Kick's law) is proposed:

$$
F-W=A_{1} d^{2}
$$

where $A_{1}$ is the load independent microhardness constant. The values of $W$ and $A_{1}$ are calculated from the linear plotting of $F$ versus $d^{2}$ and are also listed in Table 5. Figure 9 shows the variation of $F$ versus $d^{2}$ for $\left(\mathrm{Bi}_{1.8} \mathrm{~Pb}_{0.4}\right) \mathrm{Sr}_{2} \mathrm{Ca}_{2.1-x} \mathrm{Ho}_{x} \mathrm{Cu}_{3.1} \mathrm{O}_{10+\delta}$ phase with $x=$ $0.000,0.025,0.075$, and 0.200 . According to the HK approximation, Hays-Kendall microhardness $H_{\mathrm{HK}}$ and the Hays-Kendall load independent microhardness $H_{\text {HKin }}$ can be calculated by the following equations, respectively:

$$
\begin{aligned}
& H_{\mathrm{HK}}=1854.4 \times \frac{F-W}{d^{2}} \\
& H_{\mathrm{HKin}}=1854.4 \times A_{1}
\end{aligned}
$$

The values of $W$ are positive for all the samples, meaning that the applied load is sufficient to create both the elastic and the plastic deformation. The calculated values of $W$ are found to be larger than the acceptable values [75]. Similar results were observed by Kölemen et al. [32], and they reported that the

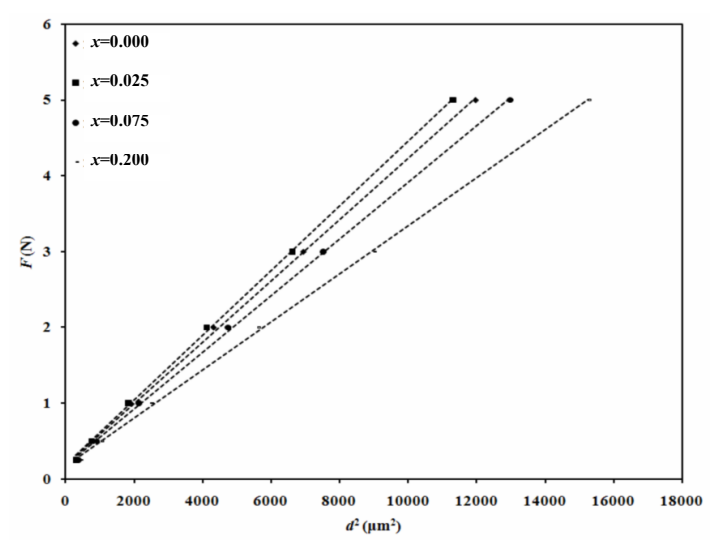

Fig. 9 Variation of the applied load $F$ with $d^{2}$ according to Hays-Kendall model for $\left(\mathrm{Bi}_{1.8} \mathrm{~Pb}_{0.4}\right) \mathrm{Sr}_{2} \mathrm{Ca}_{2.1-x} \mathrm{Ho}_{x} \mathrm{Cu}_{3.1} \mathrm{O}_{10+\delta}$ with $x=0.000,0.025,0.075$, and 0.200 . values of $W(0.128-0.163 \mathrm{~N})$ seem to be large to be accepted when studied the effect of partial substitution of $\mathrm{Ca}^{2+}$ ions by $\mathrm{Sm}^{3+}$ ions on the superconducting properties of $\mathrm{Bi}_{1.6} \mathrm{~Pb}_{0.4} \mathrm{Sr}_{2} \mathrm{Ca}_{2-x} \mathrm{Sm}_{x} \mathrm{Cu}_{3} \mathrm{O}_{y}$. Similarly, there is reason to believe that $W$ values $(0.188-0172 \mathrm{~N})$ obtained in this study seem to be large. Also, according to Ionescu et al. [76], Vickers nanoindentation tests were conducted on the similar BSCCO materials and plastic indentation impressions were observed at the load as low as $10 \mathrm{mN}$. The constant $A_{1}$ is suggested to be a measure of the load independent microhardness $H_{\mathrm{HKin}}$, and their values increase as $x$ increases to 0.025 and then decrease for $x>0.025$, confirming the experimental variation of $H_{\mathrm{V}}$ with $x$.

\section{2.3 Elastic/plastic deformation model}

Bull et al. [77] proposed that the dependence of indentation size on the applied load can be obtained by way of the equation:

$$
F=A_{2}\left(d+d_{0}\right)^{2}
$$

where $A_{2}$ is a constant and $d_{0}$ is related to $d$ plastic deformation. The values of $A_{2}$ and $d_{0}$ are calculated from $F^{1 / 2}$ versus $d$ curves for all the samples and are listed in Table 5. Figure 10 shows the variation of

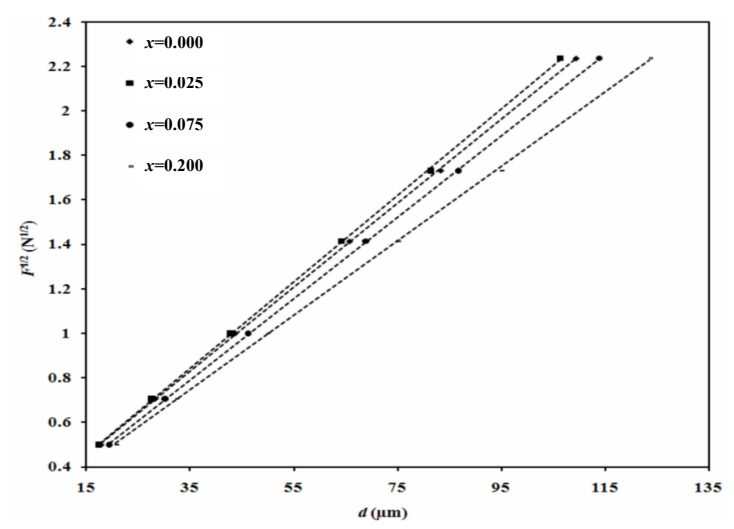

Fig. 10 Plots of $F^{1 / 2}$ versus $d$ according to elastic/plastic

\begin{tabular}{|c|c|c|c|c|c|c|c|c|}
\hline \multirow{2}{*}{$x$} & \multicolumn{2}{|c|}{ Meyer's law } & \multicolumn{2}{|c|}{ Hays-Kendall model } & \multicolumn{2}{|c|}{ EPD model } & \multicolumn{2}{|c|}{ PSR model } \\
\hline & $n$ & $A \times 10^{-3}\left(\mathrm{~N} / \mu \mathrm{m}^{2}\right)$ & $W(\mathrm{~N})$ & $A_{1} \times 10^{-4}\left(\mathrm{~N} / \mu \mathrm{m}^{2}\right)$ & $A_{2} \times 10^{-4}\left(\mathrm{~N} / \mu \mathrm{m}^{2}\right)$ & $d_{0}(\mu \mathrm{m})$ & $\alpha \times 10^{-3}(\mathrm{~N} / \mu \mathrm{m})$ & $\beta \times 10^{-4}\left(\mathrm{~N} / \mu \mathrm{m}^{2}\right)$ \\
\hline 0.000 & 1.66 & 2.04 & 0.188 & 4.05 & 3.56 & 9.02 & 7.88 & 3.43 \\
\hline 0.025 & 1.65 & 2.12 & 0.179 & 4.28 & 3.77 & 8.56 & 7.89 & 3.63 \\
\hline 0.050 & 1.68 & 1.74 & 0.168 & 3.95 & 3.52 & 8.19 & 6.91 & 3.42 \\
\hline 0.075 & 1.69 & 1.60 & 0.169 & 3.75 & 3.35 & 8.25 & 6.60 & 3.26 \\
\hline 0.100 & 1.67 & 1.65 & 0.172 & 3.55 & 3.15 & 8.85 & 6.72 & 3.05 \\
\hline 0.150 & 1.66 & 1.64 & 0.178 & 3.34 & 2.96 & 9.43 & 6.77 & 2.86 \\
\hline 0.200 & 1.66 & 1.57 & 0.172 & 3.17 & 2.80 & 9.63 & 6.55 & 2.71 \\
\hline
\end{tabular}
deformation model for $\left(\mathrm{Bi}_{1.8} \mathrm{~Pb}_{0.4}\right) \mathrm{Sr}_{2} \mathrm{Ca}_{2.1-x} \mathrm{Ho}_{x} \mathrm{Cu}_{3.1} \mathrm{O}_{10+\delta}$ with $x=0.000,0.025,0.075$, and 0.200 .

Table 5 Microhardness analysis results of different models for $\left(\mathrm{Bi}_{1.8} \mathrm{~Pb}_{0.4}\right) \mathrm{Sr}_{2} \mathrm{Ca}_{2.1-x} \mathrm{Ho}_{x} \mathrm{Cu}_{3.1} \mathrm{O}_{10+\delta}$ phase 
$F^{1 / 2}$ versus $d$ for $\left(\mathrm{Bi}_{1.8} \mathrm{~Pb}_{0.4}\right) \mathrm{Sr}_{2} \mathrm{Ca}_{2.1-x} \mathrm{Ho}_{x} \mathrm{Cu}_{3.1} \mathrm{O}_{10+\delta}$ phase with $x=0.000,0.025,0.075$, and 0.0200 . The elastic/plastic deformation microhardness $H_{\mathrm{EPD}}$ and the elastic/plastic deformation load independent microhardness $H_{\text {EPDin }}$ are calculated using:

$$
\begin{aligned}
& H_{\text {EPD }}=1854.4 \times \frac{F}{\left(d+d_{0}\right)^{2}} \\
& H_{\text {EPDin }}=1854.4 \times A_{2}
\end{aligned}
$$

As seen in Table 5, the value of $d_{0}$ is positive for all the samples. This means that, for this range of applied loads, the elastic deformation is observed along with plastic deformation and elastic relaxation is present. The presence of elastic deformation along with plastic deformation is the reason of ISE behavior for our samples. Also, it is found that $d_{0}$ changes randomly, and similar behavior was reported by previous studies on BSCCO system $[32,33,78]$. The constant $A_{2}$ is related to load independent hardness $H_{\text {EPDin }}$, and their values increase as $x$ increases to 0.025 and then decrease for $x>0.025$, confirming the experimental variation of $H_{\mathrm{V}}$ with $x$.

\section{2. 4 Proportional sample resistance model}

Proportional sample resistance (PSR) model which was developed by Li and Bradt [79] is successfully used for the analysis of microhardness of materials showing the ISE behavior. This model is given by the equation:

$$
F=\alpha d+\beta d^{2}
$$

where $\alpha$ is the surface energy, and the change in the $\alpha$ value is associated with the energy dispersion of the surface cracks [31]; $\beta$ is a parameter used to calculate the real microhardness. According to Eq. (13) the relation between $F / d$ against $d$ yields a straight line with slope corresponding to the parameter $\beta$, and the intercept represents the surface energy constant $\alpha$. Figure 11 represents the variation of $F / d$ against $d$ for $\left(\mathrm{Bi}_{1.8} \mathrm{~Pb}_{0.4}\right) \mathrm{Sr}_{2} \mathrm{Ca}_{2.1-x} \mathrm{Ho}_{x} \mathrm{Cu}_{3.1} \mathrm{O}_{10+\delta}$ phase with $x=$ $0.000,0.025,0.075$, and 0.200 . The calculated values of $\alpha$ and $\beta$ are listed in Table 5. The value of $\alpha$ is positive for all the samples, consisting with the results obtained from Hays-Kendall approach, where the term $\alpha d$ in the PSR model is equivalent to the constant $W$ in Hays-Kendall approach. It is clear that the value of $\alpha$ increases by increasing Ho content to $x=0.025$ and then it has a reverse trend. The enhancement can be ascribed to the dissipation of the

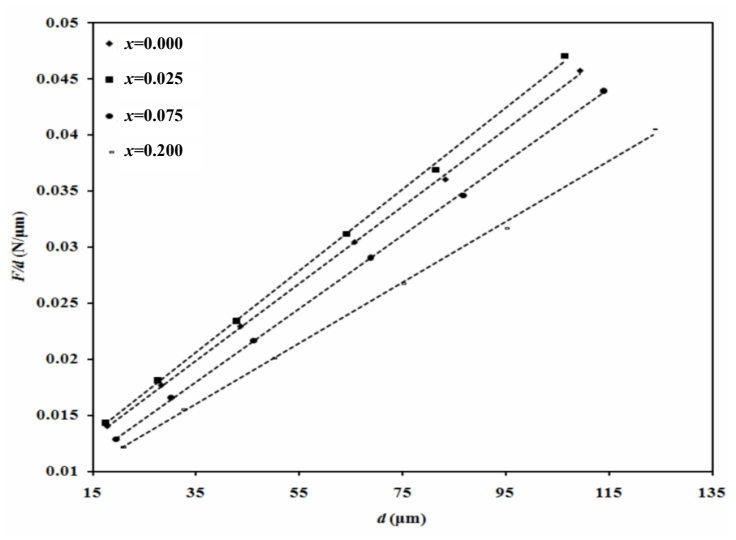

Fig. 11 Plots of $F / d$ versus $d$ according to proportional sample resistance model for $\left(\mathrm{Bi}_{1.8} \mathrm{~Pb}_{0.4}\right) \mathrm{Sr}_{2} \mathrm{Ca}_{2.1-x} \mathrm{Ho}_{x} \mathrm{Cu}_{3.1} \mathrm{O}_{10+\delta}$ with $x=0.000,0.025,0.075$, and 0.200 .

cracks at the interfaces [80]. Moreover, the constant $\beta$ is suggested to be a measure of the load independent microhardness $H_{\text {PSRin }}$ according to Eq. (15). It is noted that the values of $\beta$ and $H_{\text {PSRin }}$ confirm the experimental variation of $H_{\mathrm{V}}$ with $x$. Based on PSR model, PSR microhardness $H_{\mathrm{PSR}}$ and the PSR load independent microhardness $H_{\text {PSRin }}$ are given by the following equations, respectively:

$$
\begin{aligned}
& H_{\mathrm{PSR}}=1854.4 \times \frac{\alpha_{1} d+\beta d^{2}}{d^{2}} \\
& H_{\mathrm{PSR} i n}=1854.4 \times \beta
\end{aligned}
$$

In order to determine the consistency of the above mentioned models with our samples, the experimental and calculated microhardness at the plateau region as well as the load independent microhardness values according to each model are listed in Table 6. It is obvious from Table 6 that the true microhardness value according to the HK model $(0.751 \mathrm{GPa})$ of the sample with $x=0.000$ is lower than the hardness value in the plateau region $\left(H_{\mathrm{V}}=0.802-0.775 \mathrm{GPa}\right)$. This behavior is also observed in all the other samples. Although the HK model has been applied to BSCCO system in Refs. $[34,81,82]$ for example, the consistency is not very good in our case; it is found that $W$ seems to be large to be accepted, and the values of the true hardness calculated by this model are not in the plateau region. Therefore, one can conclude that HK approach is not suitable for describing our experimental data. Similar behavior of failure of $\mathrm{HK}$ model in BSCCO system was observed in many previous works $[14,32,33,75$, 76,78]. While, for EPD model, it is found that $d_{0}$ changes randomly, and the values of the true hardness 
calculated by this model are not in the plateau region. One can conclude that EPD approach is not suitable for describing our experimental data either. Finally, PSR model is determined as the most successful model describing the mechanical properties of our samples. Similar behavior was observed by Khalil [83] studying the influence of isothermal hot pressing-doping treatment on the microstructure, electrical, and mechanical properties of $\mathrm{Bi}_{2} \mathrm{Sr}_{3-x} \mathrm{Ca}_{x} \mathrm{Cu}_{2} \mathrm{O}_{8+\delta}$ bulk samples. Also, to confirm PSR model is the best model, the deviation percentages between the experimental and theoretical true microhardness with $x$ according to each model are calculated for $\left(\mathrm{Bi}_{1.8} \mathrm{~Pb}_{0.4}\right) \mathrm{Sr}_{2} \mathrm{Ca}_{2.1-x} \mathrm{Ho}_{x}$ $\mathrm{Cu}_{3.1} \mathrm{O}_{10+\delta}$ phase and their values are listed in Table 7. It can be seen that the deviation percentages between the experimental true microhardness and the theoretical ones obtained from PSR model are very low in comparison with the other deviation percentages obtained from the other models. In addition, Figs. 12-15 show a comparison between the experimental $H_{\mathrm{V}}$ and theoretical values calculated according to different models for $\left(\mathrm{Bi}_{1.8} \mathrm{~Pb}_{0.4}\right) \mathrm{Sr}_{2} \mathrm{Ca}_{2.1-x} \mathrm{Ho}_{x} \mathrm{Cu}_{3.1} \mathrm{O}_{10+\delta}$ phase with $x=0.000,0.025,0.100$, and 0.200 . From these figures, it is clear that the experimental true microhardness values, for all the samples, are very close to those obtained from the PSR model, followed by Hays-Kendall model. However, the values of the EPD model are found to be very far from the experimental true microhardness values. Therefore, it could be concluded that the results of the PSR model are consistent with our load independent microhardness values which can give a good explanation for the true microhardness of the studied samples.

Table 6 Variation of the experimental and calculated microhardness at the plateau region, and the load independent microhardness according to HK, EPD, and PSR models versus the substitution content for $\left(\mathrm{Bi}_{1.8} \mathrm{~Pb}_{0.4}\right) \mathrm{Sr}_{2} \mathrm{Ca}_{2.1-x} \mathrm{Ho}_{x} \mathrm{Cu}_{3.1} \mathrm{O}_{10+\delta}$ phase

\begin{tabular}{|c|c|c|c|c|c|c|c|}
\hline \multirow{2}{*}{$\mathrm{x}$} & \multirow{2}{*}{$H_{\mathrm{V}}$ in plateau region $(\mathrm{GPa})$} & \multicolumn{2}{|c|}{ Hays-Kendall model } & \multicolumn{2}{|c|}{ EPD model } & \multicolumn{2}{|c|}{ PSR model } \\
\hline & & $H_{\mathrm{HK}}(\mathrm{GPa})$ & $H_{\text {HKin }}(\mathrm{GPa})$ & $H_{\mathrm{EPD}}(\mathrm{GPa})$ & $H_{\text {EPDin }}(\mathrm{GPa})$ & $H_{\text {PSR }}(\mathrm{GPa})$ & $H_{\text {PSRin }}(\mathrm{GPa})$ \\
\hline 0.000 & $0.802-0.775$ & $0.752-0.746$ & 0.751 & $0.653-0.662$ & 0.660 & $0.812-0.770$ & 0.637 \\
\hline 0.025 & $0.840-0.820$ & $0.790-0.791$ & 0.793 & $0.688-0.702$ & 0.698 & $0.854-0.812$ & 0.674 \\
\hline 0.050 & $0.775-0.755$ & $0.732-0.730$ & 0.733 & $0.644-0.655$ & 0.652 & $0.785-0.750$ & 0.634 \\
\hline 0.075 & $0.740-0.715$ & $0.698-0.691$ & 0.695 & $0.617-0.622$ & 0.621 & $0.746-0.712$ & 0.605 \\
\hline 0.100 & $0.701-0.677$ & $0.661-0.654$ & 0.658 & $0.580-0.585$ & 0.584 & $0.706-0.673$ & 0.566 \\
\hline 0.150 & $0.661-0.639$ & $0.622-0.616$ & 0.620 & $0.543-0.550$ & 0.548 & $0.668-0.635$ & 0.531 \\
\hline 0.200 & $0.619-0.608$ & $0.583-0.587$ & 0.588 & $0.510-0.523$ & 0.519 & $0.630-0.601$ & 0.502 \\
\hline
\end{tabular}

Table 7 Percentage deviation from the measured Vickers microhardness according to different models for $\left(\mathrm{Bi}_{1.8} \mathrm{~Pb}_{0.4}\right) \mathrm{Sr}_{2} \mathrm{Ca}_{2.1-x} \mathrm{Ho}_{x} \mathrm{Cu}_{3.1} \mathrm{O}_{10+\delta}$ phase (Unit: \%)

\begin{tabular}{|c|c|c|c|c|c|c|c|}
\hline \multirow{2}{*}{$x$} & \multirow{2}{*}{ Model } & \multicolumn{6}{|c|}{$F(\mathrm{~N})$} \\
\hline & & 0.25 & 0.50 & 1.00 & 2.00 & 3.00 & 5.00 \\
\hline \multirow{3}{*}{0.000} & HK & 75.34 & 37.67 & 18.83 & 9.42 & 6.28 & 3.77 \\
\hline & EPD & 126.72 & 73.94 & 45.62 & 29.33 & 22.83 & 17.18 \\
\hline & PSR & 0.10 & 0.47 & 0.28 & -0.03 & -1.23 & 0.66 \\
\hline \multirow{3}{*}{0.025} & HK & 71.68 & 35.84 & 17.92 & 8.96 & 5.97 & 3.58 \\
\hline & EPD & 122.35 & 71.59 & 44.06 & 28.46 & 22.15 & 16.76 \\
\hline & PSR & 0.74 & 0.88 & -0.23 & -0.23 & -1.63 & 1.02 \\
\hline \multirow{3}{*}{0.050} & HK & 67.23 & 33.61 & 16.81 & 8.40 & 5.60 & 3.36 \\
\hline & EPD & 106.40 & 63.69 & 39.80 & 25.91 & 20.26 & 15.32 \\
\hline & PSR & 0.09 & 0.80 & 0.06 & -0.06 & -1.30 & 0.72 \\
\hline \multirow{3}{*}{0.075} & HK & 67.23 & 33.61 & 16.81 & 8.40 & 5.60 & 3.36 \\
\hline & EPD & 101.98 & 61.68 & 38.61 & 25.22 & 19.77 & 14.90 \\
\hline & PSR & -0.56 & 0.94 & 0.03 & 0.12 & -0.85 & 0.40 \\
\hline \multirow{3}{*}{0.100} & HK & 68.69 & 34.34 & 17.17 & 8.59 & 5.72 & 3.43 \\
\hline & EPD & 110.75 & 65.79 & 40.90 & 26.51 & 20.84 & 15.69 \\
\hline & PSR & 0.47 & 0.84 & -0.16 & -0.59 & -0.79 & 0.64 \\
\hline \multirow{3}{*}{0.150} & HK & 71.36 & 35.68 & 17.84 & 8.92 & 5.95 & 3.57 \\
\hline & EPD & 116.63 & 69.10 & 42.71 & 27.63 & 21.62 & 16.28 \\
\hline & PSR & 0.06 & 1.00 & -0.10 & -0.28 & -1.02 & 0.65 \\
\hline \multirow{3}{*}{0.200} & HK & 68.77 & 34.38 & 17.19 & 8.60 & 5.73 & 3.44 \\
\hline & EPD & 115.54 & 68.56 & 42.35 & 27.38 & 21.33 & 16.20 \\
\hline & PSR & 0.30 & 1.31 & 0.02 & -0.38 & -1.88 & 1.17 \\
\hline
\end{tabular}




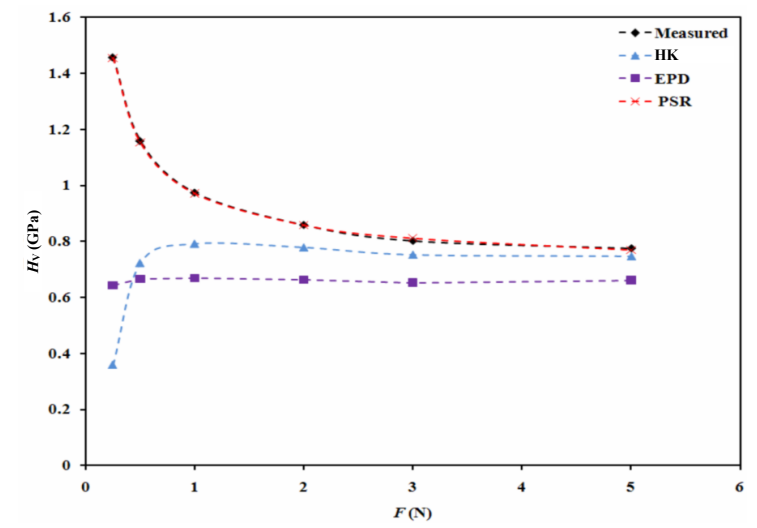

Fig. 12 Variation of the measured $H_{\mathrm{V}}$ and calculated $H_{\mathrm{V}}$ according to different models with the applied load for $\left(\mathrm{Bi}_{1.8} \mathrm{~Pb}_{0.4}\right) \mathrm{Sr}_{1.9} \mathrm{Ca}_{2.1} \mathrm{Cu}_{3.1} \mathrm{O}_{10+\delta}$ phase.

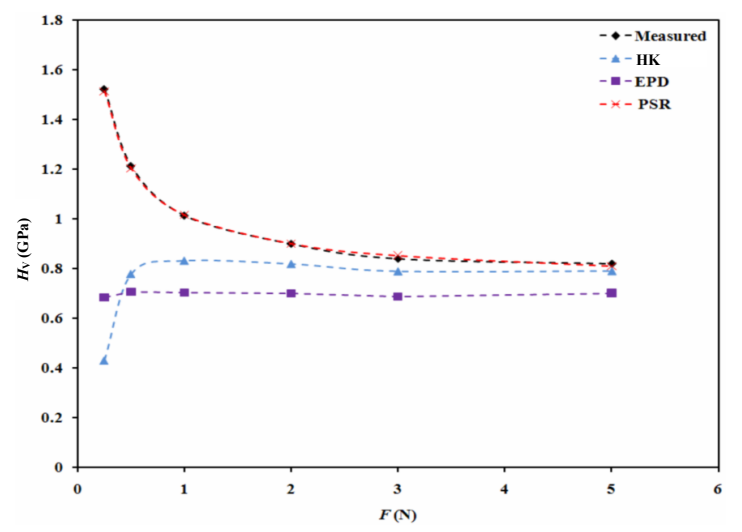

Fig. 13 Variation of the measured $H_{\mathrm{V}}$ and calculated $H_{\mathrm{V}}$ according to different models with the applied load for $\left(\mathrm{Bi}_{1.8} \mathrm{~Pb}_{0.4}\right) \mathrm{Sr}_{2} \mathrm{Ca}_{2.075} \mathrm{Ho}_{0.025} \mathrm{Cu}_{3.1} \mathrm{O}_{10+\delta}$ phase.

\section{Conclusions}

A series of $\left(\mathrm{Bi}_{1.8} \mathrm{~Pb}_{0.4}\right) \mathrm{Sr}_{2} \mathrm{Ca}_{2.1-x} \mathrm{Ho}_{x} \mathrm{Cu}_{3.1} \mathrm{O}_{10+\delta}$ samples with $x=0.000,0.025,0.050,0.075,0.100,0.150$, and 0.200 were successfully prepared via conventional solid-state reaction technique. The experimental results showed that Ho substitution at very low percentages $(0.000<x \leqslant 0.025)$ enhanced the volume fraction of the $(\mathrm{Bi}, \mathrm{Pb})-2223$ phase, $T_{\mathrm{c}}$, and $J_{\mathrm{c}}$. While the values of $T_{\mathrm{c}}$ and $J_{\mathrm{c}}$ were decreased by increasing the Ho content up to $x=0.200$ due to the formation of weak links. Moreover, the solubility limit of Ho substituted in $(\mathrm{Bi}, \mathrm{Pb})-2223$ system was higher than that reported for the other rare-earth elements and was less detrimental to the superconductivity. The analysis of electrical resistivity according to the bipolaron model showed that the number of localized carriers and boson-boson relaxation time decreased, while the scattering cross-section increased by increasing Ho contents up to

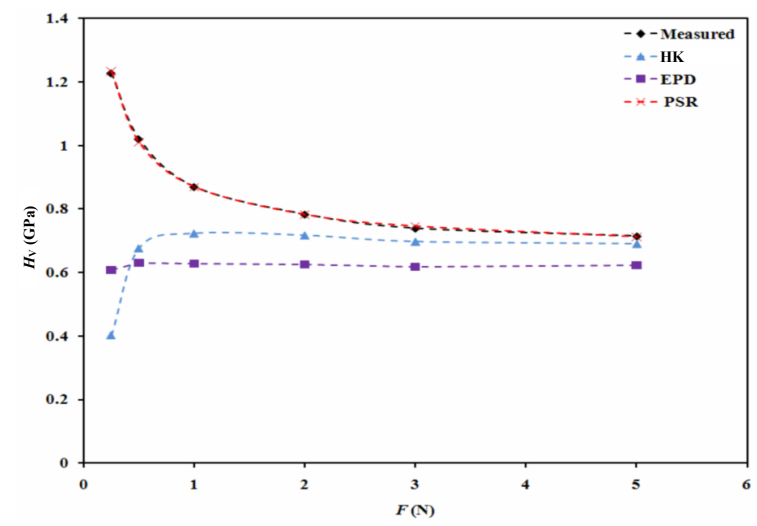

Fig. 14 Variation of the measured $H_{\mathrm{V}}$ and calculated $H_{\mathrm{V}}$ according to different models with the applied load for $\left(\mathrm{Bi}_{1.8} \mathrm{~Pb}_{0.4}\right) \mathrm{Sr}_{2} \mathrm{Ca}_{2} \mathrm{Ho}_{0.1} \mathrm{Cu}_{3.1} \mathrm{O}_{10+\delta}$ phase.

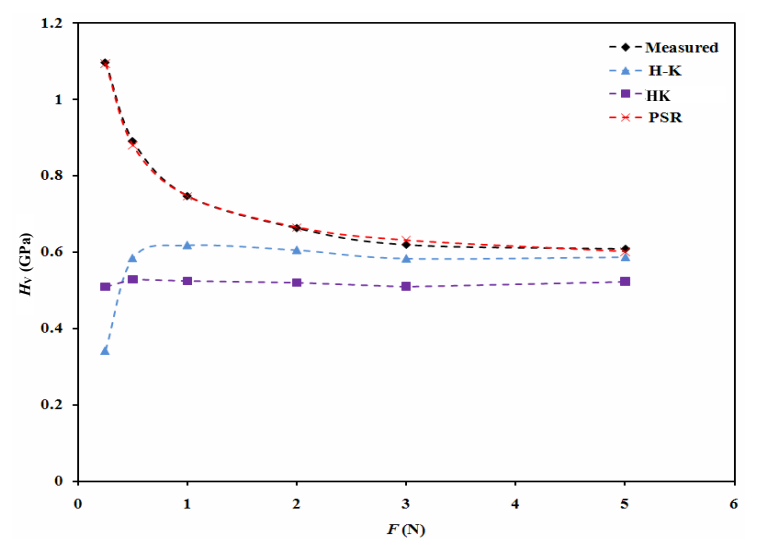

Fig. 15 Variation of the measured $H_{\mathrm{V}}$ and calculated $H_{\mathrm{V}}$ according to different models with the applied load for $\left(\mathrm{Bi}_{1.8} \mathrm{~Pb}_{0.4}\right) \mathrm{Sr}_{1.9} \mathrm{Ca}_{1.9} \mathrm{Ho}_{0.2} \mathrm{Cu}_{3.1} \mathrm{O}_{10+\delta}$ phase.

$x=0.025$. This result confirmed the increase in $T_{\mathrm{c}}$ at $x=0.025$. By distinguishing the contrast of $T_{\mathrm{c}}$ and $T^{*}$ versus Ho content, it can be concluded that transport properties is determined by the spin fluctuation scattering. Finally, the Vickers microhardness results indicated that $H_{\mathrm{V}}$ increased as $x$ increased from 0.000 to 0.025 and it had a normal ISE behavior. The results of the microhardness were examined using different models such as Meyer's law, Hays-Kendall approach, elastic/plastic deformation model, and PSR model. The PSR model was found to be the most successful model describing the mechanical properties of the studied samples.

\section{Acknowledgements}

This work was performed in the Superconductivity and Metallic Glass Lab, Physics Department, Faculty of Science, Alexandria University, Alexandria, Egypt. 


\section{References}

[1] Bilgili O, Kocabaş K. Effects of Gd substitution on magnetic, structural and superconducting properties of $\mathrm{Bi}_{1.7-x} \mathrm{~Pb}_{0.3} \mathrm{Gd}_{x} \mathrm{Sr}_{2} \mathrm{Ca}_{2} \mathrm{Cu}_{3} \mathrm{O}_{y}$. J Mater Sci: Mater El 2015, 26: $1700-1708$.

[2] Erdem M, Özturk Ö, Yucel E, et al. Effect of Gd addition on the activation energies of $\mathrm{Bi}-2223$ superconductor. Physica B 2011, 406: 705-709.

[3] Özkurt B, Madre MA, Sotelo A, et al. Relationship between growth speed, microstructure, mechanical and electrical properties in $\mathrm{Bi}-2212 / \mathrm{Ag}$ textured composites. J Supercond Nov Magn 2012, 25: 799-804.

[4] Gündoğmuş H, Özçelik B, Özkurt B, et al. Physical, mechanical and magnetic properties of the $\mathrm{Yb}$-substituted $\mathrm{Bi}_{2} \mathrm{Sr}_{2} \mathrm{Ca}_{1} \mathrm{Cu}_{2} \mathrm{O}_{y}$ textured superconductor. $J$ Supercond Nov Magn 2013, 26: 111-115.

[5] Bal S, Dogruer M, Yildirim G, et al. Role of cerium addition on structural and superconducting properties of Bi-2212 system. J Supercond Nov Magn 2012, 25: 847-856.

[6] Zargar Shoushtari M, Mousavi Ghahfarokhi SE. A study of the magnetic properties of $\mathrm{Bi}_{1.64-x} \mathrm{~Pb}_{0.36} \mathrm{Cd}_{x} \mathrm{Sr}_{2} \mathrm{Ca}_{2} \mathrm{Cu}_{3} \mathrm{O}_{y}$ superconductor. J Supercond Nov Magn 2011, 24: 1505-1511.

[7] Abou-Aly AI, Abdel Gawad MMH, Awad R, et al. Improving the physical properties of $(\mathrm{Bi}, \mathrm{Pb})-2223$ phase by $\mathrm{SnO}_{2}$ nano-particles addition. J Supercond Nov Magn 2011, 24: 2077-2084.

[8] Yildirim G, Bal S, Yucel E, et al. Effect of Mn addition on structural and superconducting properties of $(\mathrm{Bi}, \mathrm{Pb})-2223$ superconducting ceramics. J Supercond Nov Magn 2012, 25: 381-390.

[9] Sarun PM, Vinu S, Shabna R, et al. Properties of superconducting, polycrystalline dysprosium-doped $\mathrm{Bi}_{1.6} \mathrm{~Pb}_{0.5} \mathrm{Sr}_{2-x} \mathrm{Dy}_{x} \mathrm{Ca}_{1.1} \mathrm{Cu}_{2.1} \mathrm{O}_{8+\delta}(0 \leqslant x \leqslant 0.5)$. Mater Res Bull 2009, 44: 1017-1021.

[10] Sedky A. The impact of Y substitution on the $110 \mathrm{~K}$ high $T_{\mathrm{c}}$ phase in a $\mathrm{Bi}(\mathrm{Pb}): 2223$ superconductor. $J$ Phys Chem Solids 2009, 70: 483-488.

[11] Mihalache V, Deac IG, Pop AV, et al. The pinning force density in polycrystalline $\mathrm{Bi}_{1.8} \mathrm{~Pb}_{0.4} \mathrm{Sr}_{2} \mathrm{Ca}_{2-x} \mathrm{Y}_{x} \mathrm{Cu}_{3} \mathrm{O}_{y}$ multiphase systems. Curr Appl Phys 2011, 11: 1010-1014.

[12] Marconi D, Stiufiuc G, Pop AV. Effect of partial substitution of Ca by $4 \mathrm{f}$ elements on dissipative processes in Bi:2223 superconductors. Journal of Physics Conference Series 2009, 153: 012022.

[13] Terzioglu C, Yilmazlar M, Ozturk O, et al. Structural and physical properties of $\mathrm{Sm}$-doped $\mathrm{Bi}_{1.6} \mathrm{~Pb}_{0.4} \mathrm{Sr}_{2} \mathrm{Ca}_{2-x} \mathrm{Sm}_{x}$ $\mathrm{Cu}_{3} \mathrm{O}_{y}$ superconductors. Physica $C$ 2005, 423: 119-126.

[14] Yilmazlar M, Cetinkara HA, Nursoy M, et al. Thermal expansion and Vickers hardness measurements on $\mathrm{Bi}_{1.6} \mathrm{~Pb}_{0.4} \mathrm{Sr}_{2} \mathrm{Ca}_{2-x} \mathrm{Sm}_{x} \mathrm{Cu}_{3} \mathrm{O}_{y}$ superconductors. Physica $C$ 2006, 442: 101-107.

[15] Görür O, Küçükömeroğlu T, Terzioğlu C, et al. The effect of $\mathrm{Ag}$ diffusion on properties of $\mathrm{YBa}_{2} \mathrm{Cu}_{3} \mathrm{O}_{7-x}$ thin films produced by electron beam deposition techniques. Physica C 2005 418: 35-42.

[16] Hawa JS, Azhan H, Yahya SY, et al. The effect of Eu substitution onto $\mathrm{Ca}$ site in $\mathrm{Bi}(\mathrm{Pb})-2223$ superconductor via co-precipitation method. J Supercond Nov Magn 2013, 26: 979-983.

[17] Alexandrov AS, Zavaritsky VN, Dzhumanov S. Hall effect and resistivity in underdoped cuprates. Phys Rev B 2004, 69: 052505.

[18] Alexandrov AS, Mott NF. Lattice and spin bipolarons in metal oxides and doped fullerenes. J Supercond 1994, 7: 599-605.

[19] Alexandrov AS. Critical temperature of high- $T_{\mathrm{c}}$ superconductors in the bipolaron model. AIP Conf Proc 2003, 695: 42.

[20] Hague JP, Kornilovitch PE, Alexandrov AS. Trapping of lattice polarons by impurities. Phys Rev B 2008 78: 092302.

[21] Aghabagheri S, Mohammadizadeh MR. The bipolaron model in the normal state of Pr-doped $\mathrm{GdBa}_{2} \mathrm{Cu}_{3} \mathrm{O}_{7}$ superconductors. Supercond Sci Tech 2010, 23: 045003.

[22] Sadovskii MV. Pseudogap in high-temperature superconductors. Physics-Uspekhi 2001, 44: 515.

[23] $\mathrm{Xu} \mathrm{S}, \mathrm{Wu} \mathrm{XS}$, Liu G, et al. Structure and spin gap in $\mathrm{YBa}_{2} \mathrm{Cu}_{3-x} \mathrm{Gd}_{x} \mathrm{O}_{7-\delta}$ superconductors. Physica $C 2004,417$ : 63-68.

[24] Mohammadizadeh MR, Akhavan M. Pseudogap in Gd-based 123 HTSC. Physica B 2003, 336: 410-419.

[25] Naqib SH, Cooper JR, Tallon JL, et al. Doping phase diagram of $\mathrm{Y}_{1-x} \mathrm{Ca}_{x} \mathrm{Ba}_{2}\left(\mathrm{Cu}_{1-y} \mathrm{Zn}_{y}\right)_{3} \mathrm{O}_{7-\delta}$ from transport measurements: Tracking the pseudogap below $T_{\mathrm{c}}$. Phys Rev B 2005, 71: 054502.

[26] Prokof'ev DD, Volkov MP, Boikov YA. Pseudogap and its temperature dependence in YBCO from the data of resistance measurements. Phys Solid State + 2003, 45: $1223-1232$.

[27] Babaev E, Kleinert H. Nonperturbative XY-model approach to strong coupling superconductivity in two and three dimensions. Phys Rev B 1999, 59: 12083.

[28] Awad R, Abou-Aly AI, Abdel Gawad MMH, et al. The influence of $\mathrm{SnO}_{2}$ nano-particles addition on the Vickers microhardness of $(\mathrm{Bi}, \mathrm{Pb})-2223$ superconducting phase. J Supercond Nov Magn 2012, 25: 739-745.

[29] Awad R, Abou Aly AI, Kamal M, et al. Mechanical properties of $\left(\mathrm{Cu}_{0.5} \mathrm{Tl}_{0.5}\right)-1223$ substituted by $\operatorname{Pr}$. J Supercond Nov Magn 2011, 24: 1947-1956.

[30] Mohammed NH, Abou-Aly AI, Ibrahim IH, et al. Effect of nano-oxides addition on the mechanical properties of $\left(\mathrm{Cu}_{0.5} \mathrm{Tl}_{0.5}\right)-1223$ phase. J Supercond Nov Magn 2011, 24: 1463-1472.

[31] Abdeen W, Mohammed NH, Awad R, et al. Influence of nano-Ag addition on the mechanical properties of $\left(\mathrm{Cu}_{0.5} \mathrm{Tl}_{0.5}\right)-1223$ superconducting phase. $J$ Supercond Nov Magn 2013, 26: 3235-3245. 
[32] Kölemen U, Uzun O, Y1lmazlar M, et al. Hardness and microstructural analysis of $\mathrm{Bi}_{1.6} \mathrm{~Pb}_{0.4} \mathrm{Sr}_{2} \mathrm{Ca}_{2-x} \mathrm{Sm}_{x} \mathrm{Cu}_{3} \mathrm{O}_{y}$ polycrystalline superconductors. J Alloys Compd 2006, 415: 300-306.

[33] Aydin H, Cakiroglu O, Nursoy M, et al. Mechanical and superconducting properties of the $\mathrm{Bi}_{1.8} \mathrm{~Pb}_{0.35} \mathrm{Sr}_{1.9} \mathrm{Ca}_{2.1} \mathrm{Cu}_{3}$ $\mathrm{Gd}_{x} \mathrm{O}_{y}$ system. Chin J Phys 2009, 47: 192-206.

[34] Terzioglu C. Investigation of some physical properties of Gd added Bi-2223 superconductors. J Alloys Compd 2011, 509: 87-93.

[35] Mohammed NH, Awad R, Abou-Aly AI, et al. Optimizing the preparation conditions of $\mathrm{Bi}-2223$ superconducting phase using $\mathrm{PbO}$ and $\mathrm{PbO}_{2}$. Materials Sciences and Applications 2012, 3: 224-233.

[36] Leenders A, Mich M, Freyhard HC. Influence of thermal cycling on the mechanical properties of VGF melt-textured YBCO. Physica C 1997, 279: 173-180.

[37] Abou-Aly AI, Awad R, Mahmoud SA, et al. EPR studies of $(\mathrm{Bi}, \mathrm{Pb})-2223$ phase substituted by Ruthenium ions. J Alloys Compd 2011, 509: 7381-7388.

[38] Nursoy M, Yilmazlar M, Terziogl C, et al. Transport, microstructure and mechanical properties of $\mathrm{Au}$ diffusion-doped Bi-2223 superconductors. J Alloys Compd 2008, 459: 399-406.

[39] Terzioglu C, Aydin H, Ozturk O, et al. The influence of Gd addition on microstructure and transport properties of Bi-2223. Physica B 2008, 403: 3354-3359.

[40] $\mathrm{Pu} \mathrm{MH}$, Song $\mathrm{WH}$, Zhao B, et al. Enhanced flux pinning in $(\mathrm{Bi}, \mathrm{Pb})-2223 / \mathrm{Ag}$ tapes by slight Pr-doping. Physica $C$ 2001, 361: 181-188.

[41] Koyama S, Endo U, Kawai T. Preparation of single $110 \mathrm{~K}$ phase of the $\mathrm{Bi}-\mathrm{Pb}-\mathrm{Sr}-\mathrm{Ca}-\mathrm{Cu}-\mathrm{O}$ superconductor. Japanese Journal of Applied Physics 1988, 27: L1861-L1863.

[42] Abou-Aly AI, Mahmoud SA, Awad R, et al. Electrical resistivity and magnetoresistance studies of $(\mathrm{Bi}, \mathrm{Pb})-2223$ phase substituted by Ru. J Supercond Nov Magn 2010, 23: 1575-1588.

[43] Kocabaş K, Şakiroğlu S, Çiftçioğlu M, et al. The effect of $\mathrm{Zn}$ substitution of $\mathrm{Ca}$ in $\mathrm{BiPbSrCaCuO}$ superconductors sintered at $830{ }^{\circ}$ C. J Supercond Nov Magn 2009, 22: 749-754.

[44] Özkurt B. The effects of yttrium substitution in Bi-2223 superconductors. J Mater Sci: Mater El 2013, 24: 758 763.

[45] Shannon RD. Revised effective ionic radii and systematic studies of interatomic distances in halides and chalcogenides. Acta Cryst 1976, A32: 751-767.

[46] Ozturk O, Akdogan M, Aydin $\mathrm{H}$, et al. Substitution of $\mathrm{Sm}$ at $\mathrm{Ca}$ site in $\mathrm{Bi}_{1.6} \mathrm{~Pb}_{0.4} \mathrm{Sr}_{2} \mathrm{Ca}_{2-x} \mathrm{Sm}_{x} \mathrm{Cu}_{3} \mathrm{O}_{y}$ superconductors. Physica B 2007, 399: 94-100.

[47] Xiong YM, Li L, Luo XG, et al. Transport properties of Ru-doped $\mathrm{La}_{1.85} \mathrm{Sr}_{0.15} \mathrm{CuO}_{4}$ and the effect of carrier concentration compensation. J Phys: Condens Matter 2003, 15: 1693-1704.
[48] Aksan MA, Yakinci ME, Kadowaki K. The effect of Ru substitution on the thermal, structural and magnetic properties of $\mathrm{Bi}_{3} \mathrm{Sr}_{2} \mathrm{Ca}_{2} \mathrm{Cu}_{3} \mathrm{O}_{\delta}$ superconducting system. J Supercond Nov Magn 2010, 23: 371-380.

[49] Bilgili O, Selamet Y, Kocabaş K. Effects of Li substitution in Bi-2223 superconductors. J Supercond Nov Magn 2008, 21: 439-449.

[50] Anis-ur-Rehman M, Mubeen M. Synthesis and enhancement of current density in cerium doped $\mathrm{Bi}(\mathrm{Pb}) \mathrm{Sr}(\mathrm{Ba})-2223$ high $T_{\mathrm{c}}$ superconductor. Synthetic Metals 2012, 162: 1769-1774.

[51] Anderson PW. Hall effect in the two-dimensional Luttinger liquid. Phys Rev Lett 1991, 67: 2092.

[52] Abou Aly AI, Ibrahim IH, Awad R, et al. Stabilization of Tl-1223 phase by arsenic substitution. J Supercond Nov Magn 2010, 23: 1325-1332.

[53] Koo JH, Cho G. The spin-gap in high T-c superconductivity. J Phys: Condens Matter 2003, 15: L729-L733.

[54] Kameli P, Salamati H, Abdolhosseini I, et al. Thermally activated flux creep in the $\mathrm{Bi}_{1.66} \mathrm{~Pb}_{0.34} \mathrm{Sr}_{2} \mathrm{Ca}_{2-x} \mathrm{Mg}_{x} \mathrm{Cu}_{3} \mathrm{O}_{y}$ superconductors. Physica C 2008, 468: 137-141.

[55] Laximi Narasaiah E, Subba Rao UV, Pena O, et al. Annealing effects on $T_{\mathrm{c}}$ in $\mathrm{Bi}_{2} \mathrm{Sr}_{2} \mathrm{Ca}_{0.9} \mathrm{Y}_{0.1} \mathrm{Cu}_{2} \mathrm{O}_{8+\delta}$ system. Mat Sci Eng B 1992, 15: 37-39.

[56] Abrikosov AA, Gor'kov LP. Contribution to the theory of superconducting alloys with paramagnetic impurities. Sov Phys JETP 1961, 12: 1243.

[57] Vélez M, Cyrille MC, Kim S, et al. Enhancement of superconductivity by decreased magnetic spin-flip scattering: Nonmonotonic $T_{\mathrm{c}}$ dependence with enhanced magnetic ordering. Phys Rev B 1999, 59: 14659.

[58] Nanda Kishore K, Satyavathi S, Muralidhar M, et al. Thermoelectric power studies on the Sm substituted BPSCCO (2223) superconductors. Physica C 1995, 252: 49-53.

[59] Singh R, Gupta A, Agarwal SK, et al. Superconductivity in Pr-doped $\mathrm{Bi}_{2} \mathrm{Ca}_{2} \mathrm{Sr}_{2} \mathrm{Cu}_{3} \mathrm{O}_{y}$. Supercond Sci Technol 1998, 11: $311-314$

[60] Kothawale RR, Dole BN, Shah SS. Effect of substitution of $\mathrm{Ce}$ on superconducting properties of $\mathrm{Bi}_{1.7} \mathrm{~Pb}_{0.3} \mathrm{Sr}_{2} \mathrm{Ca}_{2-x}$ $\mathrm{Ce}_{x} \mathrm{Cu}_{3} \mathrm{O}_{10+\delta}$ system. Pramana 2002, 58: 871-875.

[61] Aliabadi A, Akhavan Farshchi Y, Akhavan M. A new Y-based HTSC with $T_{\mathrm{c}}$ above $100 \mathrm{~K}$. Physica $C$ 2009, 469: 2012-2014.

[62] Alexandrov AS, Bratkovsky AM, Mott NF. Hall-effect and resistivity of high- $T(\mathrm{c})$ oxides in the bipolaron model. Phys Rev Lett 1994, 72: 1734-1737.

[63] Esmaeili A, Sedghi H, Golzan MM, et al. The normal state properties of $\mathrm{Y}_{3} \mathrm{Ba}_{5} \mathrm{Cu}_{8-x} \mathrm{Zn}_{x} \mathrm{O}_{18-\delta}$ superconductor in bipolaron model. J Supercond Nov Magn 2011, 24: 2237-2242.

[64] Fukuyama H, Kohno H. The spin gap and extended $t-J$ model. Physica C 1997, 282-287: 124-127.

[65] Lee PA. Gauge field, Aharonov-Bohm flux, and high- $T_{\mathrm{c}}$ 
superconductivity. Phys Rev Lett 1989, 63: 680.

[66] Katona TM, Pierson SW. Zero-field current-voltage characteristics in high-temperature superconductors. Physica C 1996, 270: 242-248.

[67] Repaci JM, Kwon C, Jiang XG, et al. Absence of Kosterlitz-Thouless transition in ultra-thin YBCO films. Bulletin of the American Physical Society 1995, 40: 445.

[68] Díaz A, Mechin L, Berghuis P, et al. Observation of viscous flux flow in $\mathrm{YBa}_{2} \mathrm{Cu}_{3} \mathrm{O}_{7-\delta}$ low-angle grain boundaries. Phys Rev B 1998, 58: R2960(R).

[69] Kwak JF, Venturini EL, Ginley DS, et al. Grain decoupling at low magnetic fields in ceramic $\mathrm{YBa}_{2} \mathrm{Cu}_{3} \mathrm{O}_{7-\delta}$. In: Novel Superconductivity. Wolf SA, Kresin VZ, Eds. New York: Plenum Press, 1987: 983-991.

[70] Aloysius RP, Guruswamy P, Syamaprasad U. Enhanced flux pinning in $(\mathrm{Bi}, \mathrm{Pb})-2223$ superconductor by $\mathrm{Nd}$ addition. Supercond Sci Tech 2005, 18: 427-431.

[71] Foerster CE, Lima E, Rodrigues Jr. P, et al. Mechanical properties of Ag-doped top-seeded melt-grown YBCO pellets. Braz J Phys 2008, 38: 341-345.

[72] Sangwal K, Surowska B. Study of indentation size effect and microhardness of $\mathrm{SrLaAlO}_{4}$ and $\mathrm{SrLaGaO}_{4}$ single crystals. Mater Res Innov 2003, 7: 91-104.

[73] Tickoo R, Tandon RP, Bamzai KK, et al. Microindentation studies on samarium-modified lead titanate ceramics. Mater Chem Phys 2003, 80: 446-451.

[74] Hays C, Kendall EG. An analysis of Knoop microhardness. Metallography 1973, 6: 275-282.

[75] Peng Z, Gong J, Miao H. On the description of indentation size effect in hardness testing for ceramics: Analysis of the nanoindentation data. J Eur Ceram Soc 2004, 24: 21932201.

[76] Ionescu M, Zeimetz B, Dou SX. Microhardness anisotropy of Bi-2212 crystals. Physica C 1998, 306: 213-217.
[77] Bull SJ, Page TF, Yoffe EH. An explanation of the indentation size effect in ceramics. Phil Mag Lett 1989, 59: 281-288.

[78] Ozturk O. Some physical properties and Vickers hardness measurements of Fe diffusion-doped $\mathrm{Bi}_{1.8} \mathrm{~Pb}_{0.35} \mathrm{Sr}_{1.9} \mathrm{Ca}_{2.1}$ $\mathrm{Cu}_{3} \mathrm{O}_{y}$ superconductors. J Mater Sci: Mater El 2012, 23: 1235-1242.

[79] Li H, Bradt RC. The microhardness indentation load/size effect in rutile and cassiterite single crystals. J Mater Sci 1993, 28: 917-926.

[80] Bobrov VS. Deformation, structure and properties of ceramics and crystals of high- $T_{\mathrm{c}}$ superconductors. Mat $S c i$ Eng A 1993, 164: 146-152.

[81] Ozturk O, Erdem M, Asikuzun E, et al. Investigation of indentation size effect (ISE) and micro-mechanical properties of $\mathrm{Lu}$ added $\mathrm{Bi}_{2} \mathrm{Sr}_{2} \mathrm{CaCu}_{2} \mathrm{O}_{y}$ ceramic superconductors. J Mater Sci: Mater El 2013, 24: 230-238.

[82] Koralay H, Arslan A, Cavdar S, et al. Structural and mechanical characterization of $\mathrm{Bi}_{1.75} \mathrm{~Pb}_{0.25} \mathrm{Sr}_{2} \mathrm{Ca}_{2} \mathrm{Cu}_{3-x}$ $\mathrm{Sn}_{x} \mathrm{O}_{10+y}$ superconductor ceramics using Vickers microhardness test. J Mater Sci: Mater El 2013, 24: 4270-4278.

[83] Khalil SM. Influence of isothermal hot pressing-doping treatment on the electrical and mechanical properties of bulk Bi-Sr-Ca-Cu-O. AIP Advances 2012, 2: 042183.

Open Access The articles published in this journal are distributed under the terms of the Creative Commons Attribution 4.0 International License (http://creativecommons. org/licenses/by/4.0/), which permits unrestricted use, distribution, and reproduction in any medium, provided you give appropriate credit to the original author(s) and the source, provide a link to the Creative Commons license, and indicate if changes were made. 